\title{
Cambio y continuidad en el Debate sobre la Dependencia y el Imperialismo
}

\author{
INTRODUCCION
}

Este trabajo tiene básicamente dos objetivos: en primer lugar, analizar y clarificar el desarrollo y los principales focos de discusión de lo que ha venido en llamarse "teoría de la dependencia"1 y, segundo, introducir nuevos conceptos y temas de análisis dentro de este mismo marco teórico, considerando especialmente los diversos cambios que ha experimentado la economía política mundial antes y después de la crisis del petróleo.

En términos de organización, este ensayo está dividido en tres partes: la primera sección incluye un análisis histórico-descriptivo del surgimiento y desarrollo de la perspectiva teórica de la dependencia en América Latina; la segunda comprende un examen crítico de temas y/o problemas claves que han sido el foco primordial de la discusión sobre la dependencia y el imperialismo $y$, finalmente, la última parte introduce el concepto de dependencia estratégica; es decir, el grado en que un país capitalista avanzado depende de fuentes externas para el abastecimiento de minerales estratégicos baratos esenciales para su economía y defensa nacional. Esta última sección - a diferencia de la mayor parte del debate sobre la dependencia que se ha concentrado, con buenas razones, en el impacto del imperialismo en las estructuras de clase, economías y culturas de la periferia - analiza algo de lo que ha sucedido y sucede en los centros a medida que el imperialismo se desarrolla. Es decir, esta parte final pretende estudiar, desde una perspectiva dialéctica, un aspecto hasta ahora no discutido suficientemente en toda la literatura sobre el imperialismo y la dependencia.

\footnotetext{
${ }^{1}$ Introducciones adecuadas a la literatura sobre la dependencia pueden hallarse en James D. Cockcrofi, Andre Gunder Frank y Dale Johnson, Dependence and Underdevelopment: Latin America's Political Economy (Garden City, N.Y.: Anchor Books, 1972); Ronald Chilcote y Jocl Edelstein (eds.), Latin America: The Struggle with Dependency and Beyond (New York: John Wiley and Sons, 1974); Ronald H. Chilcote, "A Critical Synthesis of the Dependency Literature", Latin American Perspectives, vol. 1, No 1, Spring 1974; Ronald Chilcote, "A Question of Dependency", Latin American Research Review, vol. XII, $\mathrm{N}^{\circ} 2$. 1978; Frank Bonilla y Robert Girling (eds.) Structures of Dependency (Stanford: Stanford University Press, 1973); Charles K. Wilber (ed.) The Political Economy of Development and Underdevelopment (New York: Random House, 1973); Helio Jaguaribe (ed.) La Dependencia Política-Económica de América Latina (México: Siglo Xxi, 1969); Antonio Murga Frasinetti y Guillermo Boils (eds.), América Latina Dependencia y Subdesarrollo (San José de Costa Rica: Editorial Universitaria Centroamericana, 1973).
} 


\section{EL DESARROLLO DE LA PERSPECTIVA TEORICA DE LA DEPENDENCIA: FASES HISTORICAS}

Los académicos conservadores que han analizado el problema del subdesarrollo en América Latina, y el resto de las zonas subdesarrolladas, han tradicionalmente afirmado que el progreso en esas regiones sólo puede ocurrir a través de la penetración del "modernismo" a aquellas áreas que ellos consideran "atrasadas" y "arcaicas". Por otra parte, los teóricos ortodojos del comercio internacional han recomendado que los países subdesarrollados no necesitan industrializarse en vista de las "ventajas comparativas" que se derivan de la especialización en producción de materias primas para la exportación.

Los analistas del subdesarrollo en América Latina criticaron por mucho tiempo estos análisis ortodojos. Sin embargo, los puntos de vista de los primeros fueron generalmente ignorados, excepto en pequeños círculos académicos, hasta que Raúl Prebisch y lo que André Gunder Frank denomina los teóricos de la "vieja dependencia" en la Comisión Económica para América Latina (CEPAL) comenzaron durante la década del ' 50 ' a cuestionar las hipótesis y conclusiones convencionales del comercio internacional.

Basado en argumentos empíricos, Prebisch argumentó que debilidades a largo plazo en los precios de las materias primas invalidaban los resultados positivos que se suponía derivaban de la tesis de las ventajas comparativas. Después de dividir analíticamente al mundo en un centro desarrollado y una periferia subdesarrollada, Prebisch demostró no sólo que no había ocurrido una transferencia de progreso tecnológico hacia la periferia a través del comercio, como afirmaban los teóricos ortodojos, sino que, por el contrario, aumentos en productividad en países subdesarrollados habían sido re-canalizados hacia los centros. El académico argentino también demostró que la demanda por productos primarios varía radicalmente, lo que acarrea consecuencias negativas para los países monoproductores y que, generalmente, esta demanda crece lentamente $y$ mucho menos que el aumento del ingreso en los centros ${ }^{2}$. Estas proposiciones constituyeron la base del concepto de Prebisch sobre "el deterioro de los términos de intercambio", el mecanismo mediante el cual los centros retienen el beneficio del progreso tecnológico y expropian aumentos en productividad de los sectores exportadores de las naciones periféricas.

Los efectos negativos de esta relación de intercambio constituian según Prebisch, una dependencia externa que los paises periféricos debían superar para poder desarrollarse. Parte de la solución Prebisch -CEPAL al problema, implicaba la implementación de nuevos principios de organización económica internacional, y programas compensatorios

\footnotetext{
${ }^{2}$ Ver Raúl Prebisch, The Economic Development, of Latin America and its problems

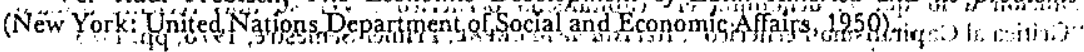

$$
489, j
$$


específicos basados no tanto en la supuesta igualdad de los estados, sino tomando especial cuenta de las necesidades de las naciones subdesarrolladas. Tanto como encargado de CEPAL y como Secretario General de la "United Nations Commission on Trade and Development" (UNCTAD), durante la década del sesenta, Prebisch fue instrumental en la articulación de demandas por trato aduanero preferencial para las exportaciones de países periféricos. Al mismo tiempo, pensadores "cepalianos" proponian políticas nacionales de "desarrollo hacia adentro" o industrialización por sustitución de importaciones, en que el comercio exterior jugaba un papel complementario: principalmente, el procurar divisas para financiar la industrialización interna ${ }^{3}$.

Debido a las diversas limitaciones de los esquemas de sustitución de importaciones, Prebisch, más tarde, sin modificar las premisas esenciales de su análisis, reorientó sus prescripciones enfatizando la promoción de exportaciones de productos manufacturados, además de cambios institucionales a nivel internacional en favor de los países pobres. La falta de efectividad de las recomendaciones de Prebisch contribuyó, a mediados de la década del sesenta, a un resurgimiento de la crítica Marxista a los modelos convencionales de desarrollo, incluyendo el de Prebisch mismo. Ese momento, en efecto marcó el comienzo de una segunda etapa en el desarrollo de la perspectiva teórica de la dependencia.

Los "teóricos de la nueva dependencia", como A.G. Frank los ha denominado, desafiaron, tal como lo habían hecho antes, las explicaciones tradicionales del subdesarrollo en los campos de la economía, sociología y ciencia política $y$, a la vez, cuestionaron las premisas y reco-

\footnotetext{
${ }^{3}$ Eñtre aquellos académicos que concuerdan, en mayor o menor medida, con las posiciones de Cepal, o las posiciones convencionales de la dependencia, se cuentan Aníbal Pinto, Miguel Wionczek, Celso Furtado y Osvaldo Sunkel.

Debemos destacar, sin embargo, que todo intento de clasificación de académicos en tipologizs, constituye, generalmente, un procedimiento inadecuado e injusto. Por ejemplo, Furtado y Sunkel bien podrian ser catalogados entre los teóricos de la "nueva" dependencia en virtud de que vinculan a la dependencia con el capitalismo, aunque su metodologia no es la del materialismo dialéctico. Más aún, el trabajo de estos dos analistas, así como el trabajo de muchos teóricos de la nueva dependencia, ha evolucionado y se ha refinado a través del tiempo, haciendo que sus contribuciones sean mucho más dificites de clasificar. Ver, por ejemplo, Celso Furtado, La Economía Latinoamericana desde la Conquista Ibérica hasta la Revolución Cubana (Santiago de Chile: Editorial Universitaria, 1969), especialmente pp. 184-213, y Celso Furtado, "The Concept of External Dependence in the Study of Underdevclopment". en Charles K. Wilber (ed.), op. cit., pp. 118-123; y Osvaldo Sunkel, "Política Nacional de Desarrollo y Dependencia Externa", Estudios Internacionales, vol. I, mayo 1967, y Osvaldo Sunkel, "Capitalismo Transnacional y Desintegración Nacional en América Latina", Estudios Internacionales, vol. Iv, N 16, enero-marzo 1971, pp. 3-61.

${ }^{4}$ Ver Raú! Prebisch, Tousards a New Trade Policy for Development (New York United Nations, 1964). Desde mediados de la década del sesenta, Prebisch ha modificado levernente su análisis sobre el subdesarrollo latinoamericano, aunque ha mantenido la mayor parte de sus premisas previas, llegando a conclusiones que podrian incluir la revolución social como solución a lo que el denomina el "capitalismo periférico". Ver su más reciente trabajo, "Crítica al Capitalismo Periférico", Revista de la CEPAL, Primer Semestre, 1976, pp. 1-73.
} 
mendaciones de la perspectiva "cepalina". Un tercer foco de crítica fue la tesis política de algunos partidos comunistas de América Latina que propiciaba una revolución en dos etapas, "basada en la premisa que América Latina era principalmente feudal y que revoluciones burguesas (la primera etapa) guiadas por una burguesía nacional debían ser apoyadas por la clase trabajadora para que el capitalismo pudiese ser construído, pasándose de esta manera a la segunda etapa de revolución socialista en un futuro incierto 2,5 .

Según Fernando Henrique Cardoso, la nueva ola de escritos sobre la dependencia y el subdesarrollo en la segunda mitad de la década de los sesenta "no representó una perspectiva metodológica nueva. Lo que pasó fue que una corriente que ya era conocida en el pensamiento latinoamericano logró hacerse oír en las discusiones que se llevaban a cabo en instituciones cercanas a ellas: CEPAL, las universidades, algunas agencias gubernamentales de planeamiento y -más aún- la comuniḍad académica norteamericana" 8 .

Cardoso estaba en lo correcto cuando indicó que académicos tales como dos Santos, A.G. Frank, Aníbal Quijano, Ruy Mauro Marini, y Cardoso mismo, no representaban una metodología nueva para el análisis del subdesarrollo en la región: la metodología seguía siendo la del materialismo dialéctico-histórico. Sin embargo, las contribuciones de ese nuevo período al tema de la dependencia - alentadas por el triunfo de la revolución cubana - también constituyeron un paso cualitativo en la discusión sobre el subdesarrollo de la región. Parafraseando a Doug Dowd: el análisis y conocimiento ya existente fue combinado de nuevas maneras, se postularon nuevas preguntas y se llegó a nuevas conclusiones, todo lo cual motivó nuevas reflexiones e investigaciones sobre temas ya explorados e inexplorados.

Mientras que los "cepalistas" y los "desarrollistas" veían las raíces de la "dependencia externa" en la naturaleza del comercio exterior y en el ordenamiento económico internacional existente, los críticos visualizaban el fenómeno de la dependencia desde una perspectiva global y en términos del sistema capitalista de producción. Estos últimos percibían un vínculo estructural entre factores domésticos y externos, con el capitalismo transnacional como el común denominador. Los análisis de la perspectiva de CEPAL - se afirmaba - no captaban estas relaciones y por eso examinaban los efectos o mejor dicho, manifestaciones de la dependencia y no los orígenes del problema. Prebisch y los teóricos asociados con CEPAL no realizaban críticas epistemológicas de las teorías ortodojas $\mathrm{y}$, más aún, no cuestionaban el sistema capitalista como parte esencial del problema de la dependencia y del subdesarrollo latinoamericano.

S'Tимтну F. Haroing, "Dependency, Nationalism and the State in Latin America", Latin American Perspectives, vol. III, N ${ }^{\circ} 4$, Fall 1976, p. 4.

"Fernando Henripue Caradoso, "The Consumption of Dependency Theory in the United States", Latin American Research Review, vol, xu, N³,1977, p. 9. 
Desde luego, algunos intelectuales vinculados con CEPAL reaccionaron con vigorosas defensas de las tesis "cepalinas" y con fuertes críticas a los críticos. Aníbal Pinto, por ejemplo, en un ataque más bien superficial de los puntos de vista de los nuevos teóricos de la dependencia manifestó concentrándose particularmente en los escritos de A. Gunder Frank, que la principal debilidad de la nueva perspectiva residía en su "completa falta de visión histórica $y$, sobre todo, de un entendimiento de la naturaleza contradictoria de todos los procesos sociales"7. Sorprendentemente, Pinto acusaba a los teóricos de la dependencia de no haber incorporado el elemento histórico y el concepto de contradicción en el análisis de fenómenos sociales, precisamente la médula y principal contribución de los "nuevos" análisis sobre dependencia basados en una metodología dialéctica e histórica.

Una de las líneas de discusión de los nuevos escritos sobre dependencia se desarrolló en torno a la tesis de la "sociedad dualista" propugnada por muchos académicos conservadores y algunos de izquierda.

La versión moderna de esta tesis tuvo sus orígenes en la interpretación de Indonesia y su sociedad por J.H. Boeke en 1942. De acuerdo a Boeke,

"En una sociedad dualista una de las dos sociedades existentes, en verdad siempre la más avanzada, habrá de ser importada desde afuera y habrá de haber aparecido en el nuevo medio sin ser capaz de eliminar o asimilar al sistema social distinto que allí se había desarrollado, resultando en que ninguno de ellos se generaliza y se transforma en característico de aquella sociedad en general",

Algunos economistas ortodojos criticaron la tesis de Boeke, pero sin rechazarla por completo, enfatizando diferentes aspectos de ella. Por ejemplo, Benjamín Higgins sostuvo que más bien el Dr. Boeke exagera el grado de 'dualismo' en países como Indonesia; el contraste entre los sectores avanzados y retrasados me parece son menores de lo que Boeke afirma, y parecen estar disminuyendo. Tampoco considero que tal dualismo sea específicamente oriental",

Añdré Gunder Frank, en su ensayo "Dialectic, Not Dual Society", resumió adecuadamente un punto de vista que ya se había extendido ampliamente entre académicos latinoamericanos respecto de la tesis de las sociedades dualistas, cuando declaró que:

"Todas las sociedades no socialistas, dualistas o no, son partes integras y están plenamente integradas en el sistema imperialista y su liberación de sus efectos de explotación y subdesarrollo cs posible sólo bajo

${ }^{7}$ Anibal. Pinto, Tres Ensayos sobre Chile y América Latina (Buenos Aires: Ediciones Soler, 1971), pp. 12-13.

J.H. BoEkE, "Dualistic Economics" en Gerald M. Meier (ed.) Leading Issues in Economic Development: Studies in Intemational Povert)' (New York: Oxford University Press,

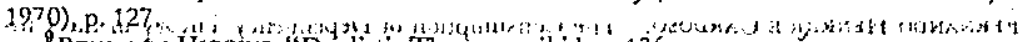

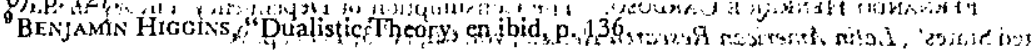


Lna estrategia Marxista-Leninista de combate contra el capitalismo imperialista en todas las sociedades no-socialistas"10.

La conclusion de Frank era que el subdesarrollo en América Latina no podía ser explicado en términos de la supervivencia de instituciones arcaicas, y/o la existencia de déficits de capital en regiones supuestamente aisladas del desarrollo histórico mundial. "Por el contrario -escribía Frank- el subdesarrollo fue y aún es generado por el mișmo proceso histórico que también generó el desarrollo económico: el desarrollo del capitalismo mismo" "En otras palabras, Frank entendía el subdesarrollo como el resultado de la incorporación integral de los países que hoy día son pobres, en el sistema capitalista que ya desde hace mucho tiempo predomina a nivel mundial.

Eduardo Galeano concordó con el análisis de Frank cuando declaró que:

"América Latina es la región de las venas abiertas. Todo, desde el descubrimiento hasta nuestros días, ha sido transformado en capital Europeo -o más tarde Norteamericano-, y como tal se ha acumulado en centros de poder lejanos. Todo: la tierra, sus frutos y sus profundidades llenas de riquezas, el pueblo y su capacidad para trabajar y consumir, recursos naturales y recursos humanos. Métodos de producción y estructuras de clase han sido sucesivamente determinados desde afuera para cada área, al incorporarlos a la máquina universal del capitalismo. A cada una le ha sido asignada una función, siempre para beneficio de la metrópolis extranjera del momento, y así la eterna cadena de la dependencia se ha ido extendiendo en forma interminable"12.

Para Galeano la dialéctica del desarrollo-subdesarrollo significaba que "nuestra derrota siempre estuvo implícita en la victoria de otros. Nuestra riqueza siempre ha generado nuestra pobreza nutriendo la prosperidad de otros -los imperios y sus guardianes nativos" ${ }^{\prime 13}$.

Un error en la tesis de Gunder Frank - que examinaremos con más detalle más adelante- fue su afirmación que la economía latinoamericana fue de naturaleza capitalista desde el período de la conquista ibérica. En su esfuerzo por destruir la tesis que describía a América Latina como "feudal", y sabiendo que durante la colonia la economía latinoamericana estaba dominada por el capital comercial, Frank pasó del nivel de la circulación al nivel de la producción al concluir que desde el periodo colonial la región se había caracterizado por un modo de producción

\footnotetext{
${ }^{10}$ Andre. Gunder Frank, "Dialectic, Not Dual Society" en A.G. Frank, Latin America: Underdevelopment or Revolution (New York: Monthly Revicw Press, 1969), p. 221.

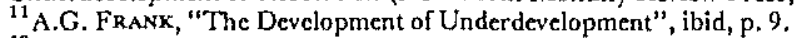

${ }^{12}$ Eduardo Galeano, Open Veins of Latin America: Five Centuries of the Pillage of a Continent (New York: Monthly Review Press, 1973), p. 12.

${ }^{13}$ Loc. cit.
} 
capitalista. Por el contrario, la gran mayoría de los estudiosos de la dependencia piensa que la economía de América Latina era "pre-capitalista", es decir que, a pesar de que en aquel entonces existían modos de producción cercanos al feudalismo, la economía en general no era feudal, ya que estaba dedicada a la producción de bienes, y estaba dominada por un capital mercantil y financiero, aunque tampoco era capitalista ya que las características que distinguen un modo de producción capitalista, que sólo existe bajo el capital industrial, estaban ausentes.

En todo caso, Frank contribuyó al estudio de la dependencia en América Latina al sugerir en forma convincente que el desarrollo internacional del capitalismo explica el subdesarrollo de los países pobres de la región. La contribución de Frank fue importante, además, porque reafirmó que el análisis del subdesarrollo y la dependencia no podía separarse del proceso mundial de expansión capitalista, especialmente en su etapa avanzada de imperialismo.

Según Theotonio dos Santos "Lenin, Bujarin y Rosa Luxemburgo, los principales representantes marxistas de la teoría del imperialismo... no estudiaron el tema del imperialismo desde la perspectiva de los países subdesarrollados"14. Franz Hinkelammert manifestó su acuerdo con dos Santos al declarar que las teorías clásicas del imperialismo "prestan poca importancia al estudio de lo que ocurre en el mundo dependiente. La nueva estructura económica periférica no constituye un elemento principal de esas teorias"15. Aunque estas dos afirmaciones están básicamente en lo correcto, también es cierto que Lenin, en su clásica obra sobre el imperialismo, reconoció el desarrollo incipiente de un fenómeno de dependencia en las sociedades subdesarrolladas. En efecto, Lenin escribió muy claramente que:

"...el capital financiero $y$ su correspondiente política exterior, que se reduce a la lucha entre las Grandes Potencias por la división económica y política del mundo, da origen a una variedad de formas transitorias de dependencia estatal. Típicos de esta época son no sólo los dos principales grupos de países: aquellos que poseen colonias y las colonias inismas, sino que también la diversa variedad de países dependientes que, oficialmente, son independiente en lo político, pero que en realidad, están envueltos en la red de dependencia financiera y diplomálica. Ya nos hemos referido a una forma de dependencia - la semicolonia. Un ejemplo de otra la constituye Argentina... Una variedad algo diferente de dependencia financiera y diplomática, acompañada de independencia política, la ofrece Portugal... Relaciones de esta clase siempre han existido entre estados grandes y pequeños, pero en la época del imperialismo capi-

\footnotetext{
${ }^{14}$ Theotonio dos Santos, Dependencia y Cambio Social (Caracas: Universidad Central de Venezuela, 1974), p. 39.

${ }^{15}$ Franz Hinkelammert, Dialéctica del Desarrollo Desigual (Valparaíso, Chile: Ediciones Universitarias de Valparaiso, 1972), p. 76.
} 
talista se transforman en un sistema general, forman parte de la suma lotal de relaciones 'dividiendo al mundo', se transforman en anillos de una cadena orgánica de operaciones del capital financiero mundial (énfasis nuestro)

Conviene recalcar que Lenin nunca negó que en el pasado hubiesen existido relaciones de dependencia entre paises grandes y pequeños. Lo importante era, sin embargo, que durante la época del imperialismo aqueIlas relaciones de dependencia constituian un sistema general, un producto estructural de la operación del capital financiero internacional.

Aníbal Quijano, entre otros, percibió esta diferencia cualitativa cuando escribió que:

"...siempre que se enfrentan los intereses dominantes de sociedades de desigual poder, la situación que se produce es conflictiva y puede, eventualmente, llevar a la dependencia; pero ella misma no constituye una situación de dependencia... las relaciones de depedencia aparecen sólo cuando las sociedades implicadas forman parte de una misma unidad estructural de interdependencia, dentro de la cua! un sector es dominante sobre los demás, lo que constituye uno de los rasgos definitorios del sistema de producción y de mercado del capitalismo actual"17.

En resumen, de acuerdo a Quijano, la dependencia es "un sistema particular de interdependencia en el universo capitalista, dentro del cual un sector es dominante sobre los demás"18.

De manera similar, Theotonio dos Santos sostuvo que "uno debe entender claramente que sólo el capitalismo industrial y, hasta cierto punto, su predecesor mercantil del siglo 16 al 18 , han producido sociedades dependientes. Se debe diferenciar este tipo de dependencia de una simple relación de interdependencia entrc pueblos y naciones, o aún de una situación de sumisión relativa..."19.

Haciéndose eco de uno de los argumentos de Frank, dos Santos insistió que "la realidad del llamado Tercer Mundo, y especialmente de América Latina, no puede ser entendida fuera del contexto de la expansión capitalista Europea que cambió la vida en esas áreas de una manera absolutamente incompatible con el desarrollo natural de la población nativa. Las

\footnotetext{
${ }^{10}$ V.I. LENIN, Imperialism, the Highest Stage of Capitalism (Peking: Foreign Languages Press, 1969), pp. 101-103.

"ANimal Quijano, "Dependencia, Cambio Social y Urbanización en Latinoamérica", en Fernando H. Cardoso y Francisco C. Weffort (eds.), Anérica Latina: Ensayos de Interpretación Sociológico-Politica (Santiago de Chile: Editorial Universitaria, 1970) p. 98 .

${ }^{18}$ Ibid., p. 99.

"Theotonio dos Santos, "Brazil: The Origins of a Crisis", en Ronald Chilcole y Joel Edelstein (cds.), op. cit., p. 417.
} 
necesidades de Europa capitalista determinaron la naturaleza de esos cambios"

Por último, Cardoso y Weffort también concordaron con la conceptualización del problema de la dependencia en la perspectiva del desarrollo capitalista mundial:

"...el núcleo de la problemática de los países dependientes no puede ser explicado sino cuando se comprende el modo de combinación entre las dimensiones que tipifican las relaciones entre grupos y clases internas, las relaciones de dominación-subordinación entre países en el contexto de las relaciones que caracterizan el sistema capitalista internaciona!"21.

Los teóricos de la nueva dependencia no sólo relacionaron imperialismo y dependencia sino que, como destacara Cardoso, una de sus más importantes contribuciones fue el "ir más allá de la generalidad del imperialismo para describir vínculos y mecanismos especificos existentes entre las estructuras domésticas e internácionales" del capitalismo ${ }^{22}$.

En el caso de Brasil, por ejemplo, Cardoso argumentó que la penetración imperialista produjo un tipo de desarrollo "dependiente-asociado", - quizás simple "crecimiento económico", compatible con los intereses de corporaciones transnacionales en el sector manufacturero ${ }^{23}$. El académico brasileño ha insistido que, actualmente, para la mayoría de los conglomerados transnacionales,

"...el mercado latinoamericano, si no específicamente el mercado particular de cada pais de América Latina donde aquellas corporaciones funcionan, es la meta inmediata en términos de ganancias. De allí que, hasta determinado punto, un cierto tipo de inversión extranjera requiere de alguna clase de prosperidad interna"24

Cardoso ha reconocido que este desarrollo distorsionado implica una serie de graves costos sociales a las masas pero que, de cualquier modo, efectivamente se ha dado.

La tesis de Cardoso sobre el desarrollo dependiente-asociado, y sus implicancias para las estrategias de confrontación anti-imperialista,

${ }^{20}$ Ibid., p. 415.

${ }^{21}$ Fernando Henrique Cardoso y Francisco Correa Weffort. "Introducción" en Cardoso y Weffort (eds.), op. cit., p. 33.

${ }^{22}$ Fernando-H. Cardooso, "O Inimigo de Papel", Latin American Perspectives, vol. $1, N^{\circ} 1$, Spring 1974, p. 66.

${ }^{22}$ Ver Fernando H. Cardoso, "Associated-Dependent Development: Theoretical and Practical Implications", en Alfred Stepan (ed.) Authoritarian Brazil (New Haven: Yale University Press, 1973), p. 14\%.

${ }^{24}$ Fernando H. Cardoso, "Dependency and Development in Latin America", New Left Review, No74, July-August 1972, p. 90. 
ha sido severamente criticada por otros analistas de la dependencia. Por una parte, se contrapone a la idea de Gunder Frank sobre el "desarrollo del subdesarrollo", ya que la primera implica - como Cardoso reconoció- que "la dependencia, el capitalismo monopólico y el desarrollo no son términos contradictorios: ocurre una especie de desarrollo capitalista dependiente en sectores del Tercer Mundo integrados a nuevas formas de expansión monopólica"25. Examinaremos esta interrogante con mayor detalle más adelante.

Concordando con la evaluación de Cardoso sobre la dependencia, en el sentido que va "más allá de la generalidad del imperialismo", dos Santos, en su trabajo Dependencia y Cambio Social distinguió varios tipos de dependencia asociados con diferentes fases históricas que culminan en la presente etapa de la "nueva dependencia", en que la producción industrial en la periferia está condicionada, de diferentes maneras, por las necesidades urgente del mercado internacional de bienes de capita ${ }^{26}$,

El concepto de dependencia, según un gran porcentaje de estudiosos de la "nueva dependencia", debe ser visualizado desde una perspectiva histórico-estructural que sobrepese la distinción analítica entrc factores internos y externos que tiende ocultar la unidad estructural existente entre ambos. El concepto de dependencia, entonces supera la dicotomía "externo-interno", "mundo desarrollado-mundo subdesarrollado", incorporándolos en una sola estructura: el sistema capitalista internacional. La aparente oposición entre desarrollo y subdesarrollo simplemente representa dos aspectos reciprocos y complementarios de un mismo proceso: la expansión internacional del capital que dio origen a los fenómenos del imperialismo y de la dependencia. Para resumir, la perspectiva de la dependencia es esencialmente dialéctica ya que pretende analizar el subdesarrollo en la periferia vinculándolo al desarrollo capitalista del centro. Es decir, pretende conocer y analizar el todo y no sólo las partes aisladas.

Finalmente, luego de una revisión cuidadosa de la abundante literatura sobre la nueva dependencia hemos identificado las siguientes proposiciones que - aunque algunas pueden no ser aceptadas por la totalidad de los analistas de la dependencia-- constituyen el núcleo central de la llamada "teoria de la dependencia".

1) El subdesarrollo no es un estado original o etapa preliminar del capilismo. Los países que ahora son pobres nunca nacieron sub-desarrollados, ya que el subdesarrollo contemporáneo de los paises pobres fue inducido.

2) El subdesarrollo contemporáneo es el producto histórico de la expansión capitalista, $y$ del establecimiento de una división internacional del trabajo que moldeó a las economías periféricas de acuerdo a las necesidades del capitalismo mundial.

\footnotetext{
${ }^{25}$ Ibid., p. 89.

${ }^{26}$ dos SANros, Dependencia y Cambio Social, op. cit., p. 55.
} 
3) El capitalismo, al ser de naturaleza transnacional, penetra cada uno de los paises actualmente subdesarrollados, de manera tal que la estructura mundial centro-periferia se reproduce a nivel nacional, resultando en flujos de plusvalía desde los campos a las zonas urbanas.

4) En Amërica Latina no existe una "burguesia nacional progresista". Los industriales nunca han sido totalmente independientes de intereses agrarios (habiendo surgido como una extensión del capital agrícola) y, más aún, comparten intereses estructurales comunes con las burguesias de los países capitalistas avanzados, en el sentido de preservar las estructuras del capitalismo transnacional que los beneficia ${ }^{27}$.

5) La ayuda militar y económica, la transferencia de tecnología, la penetración cultural y la inversión directa por medio de corporaciones multinacionales, constituyen instrumentos claves $y$ manifestaciones obvias de dependencia.

6) El desarrollo verdadero requiere el desplazamiento del orden capitalista en cada pais subdesarrollado, y la creación de un contexto socialista para el desarrollo ${ }^{28}$.

A principios de la década del 70 comenzó una tercera fase en el desarrollo de la perspectiva teórica de la dependencia. En ese periodo, la literatura sobre la "nueva dependencia" fue "descubierta" en los círculos intelectuales de los países capitalistas avanzados, especialmente en Estados Unidos. Durante esa fase histórica del —usando la frase de Cardoso"consumo de la teoría de la dependencia",

"...lo que había sido una preocupación por hacer crítica y por mantener la continuidad de previos estudios históricos, económicos, sociológicos, y políticos en América Latina, fue transformado en un artículo de consumo en varias versiones que incluye referencias al mito original, pero que en gran medida constituye la expresión de un universo intelectual muy distinto de aquel que le dio origen"29.

Esa nueva etapa histórica en el desarrollo de los escritos sobre dependencia se caracterizó por el surgimiento de dos corrientes académicas diferentes, aunque relacionadas entre si, que podríamos denominar confusionismo y distorsionismo.

La línea "confusionista" ha adoptado parte de la terminología de la

\footnotetext{
- ${ }^{27}$ Lo que no significa que conflictos, de clase intra o inter burgueses no puedan ocurrir, especialmente en torno a la manera en que la plusvalía se reparte nacional e internacionalmente.

${ }^{28}$ Discutiremos este punto detadalladamente más adelante, particularmente en relación a los escritos de Cardoso, Vasconi, Jaguaribe, y Gunder Frank.

${ }^{29}$ Fernando H. Cakmoso, "The Consumption of Dependency Theory in the United States", op. cit., p. 8.
} 
dependencia, aunque no su contenido, revelando, por lo general, un conocimiento y análisis extremadamente superficial de la literatura sobre el tema.

Guy F. Erb, por cjemplo, ha afirmado que "la teoría de la dependencia enfatiza las relaciones de poder internacional que explican el funcionamiento de la economía mundial. Visualiza la desigualdad interna como cl resultado de factores externos"30 Demostrando aún mayor confusión acerca de la naturaleza de la dependencia como la entienden los teóri$\cos$ de la "nueva dependencia", Erb ha insistido que "la teoria de la dependencia tiende a exagerar el rol de las influencias externas y consecuentemente disminuye la importancia de los obstáculos internos al desarrollo de sistema económicos, sociales y políticos más equitativos". Como si ningún analista de la "nueva dependencia" hubiese antes enfatizado la necesidad de cambios domésticos estructurales como requisito para superar la dependencia en América Latina, Erb también ha escrito que "la disminución de la dependencia frente al mundo industrializado requiere no sólo el logro de mejores acuerdos internacionales sino que, además, cambios 'dentro' de los países en vías de desarrollo" ${ }^{\text {cal }}$ (énfasis nuestro).

De manera similar, Harry Targ en un ensayo bibliográfico sobre la literatura de la dependencia - en el cuạl no hace mención alguna de los trabajos de Cardoso, Quijano, Sunkel y otros, y sólo referencia incidental a estudios menores de dos Santos y Gunder Frank- sugirió que la mayor importancia de la teoría de la dependencia era que desafiaba los modelos basados en el estado como unidad de análisis principal de las relaciones internacionales. Targ ignoró todas las contribuciones de los análisis dialécticos sobre dependencia al afirmar que los cuatro desafíos básicos de las "teorias de dominación y dependencia" eran: 1) que el sistema de estados-naciones se está transformando en un sistema de dominación global, 2) que la política transnacional está reemplazando a la política basada en el estado-nación, 3) que entrc las nuevas fuerzas que están afectando la transformación de la política internacional a un sistema de dominación global está el desarrollo y la aplicación de tecnologia, y 4) que con el surgimiento de un sistema globai - de control centralizado a través de la aplicación de tecnología y del progresivo desaparecimiento paralelo de estado-nación y de poblaciones regionales- se pone fin a la heterogeneidad de pueblos y culturas como una fuerza en la política mundial ${ }^{32}$.

Cualquiera persona medianamente familiarizada con la literatura

${ }^{30}$ GuY F. ERB, "The Developing Worid's 'Challenge' in Perspective", en Guy F. Erb y Valeriann Kalleb, (eds.) Beyond Dependency: The. Developing World Speaks Out (Washington, D.C.: Overseas Development Council, 1975), p. 139.

${ }^{31}$ Ibid., p. 140.

${ }^{32}$ HarRY R. TARe, "Global Dominance and Dependence, Post-Industrialism, and International Relations Theory", International Studies Quarterly, vol, 20, $\mathrm{N}^{\circ} 3$, September 1976, pp. 466-473. 
sobre dependencia, puede observar inmediatamente las diferencias cualitativas existentes entre aquella y las conclusiones de Targ sobre dicho tema. La importancia de las principales proposiciones de la dependencia no es tanto que constituyen un desafio a modelos de relaciones internacionales basados en el estado como unidad básica de análisis como Targ piensa, sino que cuestionan las tesis y explicaciones clásicas del subdesarrollo desde un ángulo histórico y estructural.

La línea "distorsionista", a diferencia de la "confusionista", se caracteriza por haber adoptado algo de la terminología de la dependencia, pero extirpando a propósito los elementos históricos $\mathrm{y} / \mathrm{o}$ de clase que -aunque constituyen componentes esenciales del enfoque- sus representantes rechazan. Luego que el marco teórico de la dependencia, ha sido debidamente "exorcisado", se le aplica, por lo general, al estudio de relaciones de poder entre estados, utilizando la dependencia, en el mejor de los casos, como una variable externa.

Robert Packenham, un académico representativo 'de esta última corriente, piensa que "parece lo más conveniente mantener la idea de explotación fuera de la definición de dependencia"33. Como alternativa, Packenham ha sugerido vincular el concepto de "poder" con el de dependencia, de manera que la dependencia sc definiria como: "poder o influencia relativamente baja", mientras que autonomía, o independencia, significaría "poder o influencia general relativamente alta",34. Lo irónico es que Packenham criticó el concepto de dependencia por su ambigüedad, a la vez que introducía un término mucho más ambiguo aún -y hasta "desacreditado" en círculos dedicados al estudio de la ciencia política - como es el de "poder".

Otro analista asociado con esta línea "distorsionista" es David Ray, quien opina que es un error suponer que "la dependencia económica es una consecuencia necesaria de la economía capitalista". Según Ray, "una disparidad de poder", o asimetría, es un determinante más realista de la dependencia que el capitalismo. En sus propias palabras, "el común denominador más obvio (de la dependencia) no es el capitalismo, sino simples disparidades de poder"35.

Entre los comentaristas de la dependencia que claman por una definición operativa de la dependencia, ligada al concepto de "poder" en vez de clase y/o acumulación capitalista, se cuenta a José Luis de Imaz. Este último ha escrito que relaciones de dependencia serían:

"...aquellas de subordinación, o que expresen poderes asimétricos, que se manifiestan a partir de la inevitable interdependencia, tanto en-

\footnotetext{
${ }^{33}$ Robert A. Packenham, Latin American Dependency Theories, Mimco, Stanford University, July 1974, p. 31.

${ }^{34}$ Ibid., p. 33.

3s David RAY, "The Dependency Model of. Latin American Underdevelopment: Three Basic Fallacies", Joumal of Inter American Studies and World Affairs, vol. xv, Fehrilarv 1973, p. 9.
} 
tre Estados independientes como entre éstos y organismos públicos y privados, o dentro de unidades regionales, nacionales y locales, coincidente o disimilmente en el interior de los sistemas: político, económico, científico, militar y cultural" $"$.

Una característica común de ambas corrientes asociadas con el "consumo de la teoría de la dependencia", es la conceptualización del problema de la dependencia principalmente como un desequilibrio en la relación entre dos o más actores internacionales, generalmente estadosnaciones. Por ejemplo, cuando un país subdesarrollado recibe considerable ayuda económica de una fuente específica se habla automáticamente de "dependencia", dispensado así con todo análisis de clases sociales, tan central a la literatura sobre la "nueva dependencia".

Claramente, la excesiva especialización y orientación de un país respecto a otro país, o grupo de países, ya sea para el intercambio comercial, asistencia económica $\mathrm{y} / \mathrm{o}$ inversión, es "parte" de, pero no "todo", lo que los teóricos de la nueva dependencia entienden o entendían por el concepto "dependencia". De hecho, según Cardoso, "los análisis de la dependencia en los años 1965-68 se preocupaban menos del condicionamiento externo de las economías latinoamericanas, lo que se consideraba un hecho, que del desarrollo de un tipo de análisis que capturase la naturaleza de las alianzas políticas, las ideologías y el movimiento de estructuras dentro de los países dependientes" ${ }^{\prime 38}$. Las diferencias cualitativas entre estas interpretaciones divergentes sobre la dependencia, corresponden - en cierto grado--- a las diferencias establecidas por parte del académico norteamericano James Caporaso entre "dependence" y "dependency". Según Caporaso,

"Utilizamos el término "dependence" con una connotación familiar y de sentido común, queriendo significar excesiva confiabilidad respecto a otros. En este sentido cualquier país puede depender de otro, por ejemplo, a través del comercio, transferencia de tecnología, o relaciones culturales... Por otra parte, el concepto "dependency" no tiene un equivalente de sentido común, ni tampoco puede ser reducido a una simple dimensión. En efecto, "dependency" puede sólo ser entendido (su significado original se preserva) dentro de un cierto esquema de pensamiento histórico, político y sociológico",39.

${ }^{36}$ JosE Luis dE Imaz, "¿Adiós a la Teoría de la Dependencia? Una perspectiva desde la Argentina", Estudios Internacionales, N"28, octubre-diciembre 1974, p. 55.

${ }^{3}$ Ver, por cjemplo, Kathryn Morton, Aid and Dependence: British Aid to Malawi (London: Croom Helm in Association with Overseas Development Institute, 1975).

${ }^{38}$ Fernando H. Cardoso, "The Consumption of Dependency Theory in the United States", op. cit., p. 12.

${ }^{30}$ James A. Caporaso, "Dependence, dependency, and power. in the global system: a structural and behavioral analysis", International Organization, vol. $32, \mathrm{~N}^{\circ} 1$, Winter 1978, p. 19. 
Durante la presente etapa histórica de penetración de la problematica de la dependencia en los círculos académicos de los centros, también han aparecido analistas que han contribuido de manera positiva al diálogo en torno a la dependencia y al subdesarrollo. Samir Amin, por ejemplo, ha demostrado la relevancia de la teoría de la dependencia en el estudio del subdesarrollo africano. De acuerdo a Amin, "la aceleración de la explotación colonial después de la Segunda Guerra Mundial acentuó las características estructurales del subdesarrollo en esta parte de Africa Occidental... La orientación hacia el exterior creció, y hubo un aumento de la dependencia con respecto al centro que estimuló y mantuvo este crecimiento desde afuera ${ }^{\text {"40 }}$.

Amin también señaló otros fenómenos característicos de la realidad africana específica; principalmente, que la fragmentación del árrea económica de Åfrica Occidental constituyó "una presión irresistible para la mantención de políticas y estructuras coloniales y de un 'desarrollo' colonial y que todo esto a su vez produjo, de un modo no menos irresistible, la dominación foránea y el subdesarrollo"41. Otra diferencia descubierta por Amin entre Africa Occidental y América Latina se refiere al efecto del colonialismo en las formaciones de clase nacionales. Según Amin, la colonización de Africa destruyó los estados tradicionales y los comerciantes, "reemplazándolos por el petit-blanc, el administrador o mercader colonial. Sin esta destrucción, la situación del Africa Negra se asemejaría mucho más a la situación existente en Asia o América Latina, con sus burguesías tipo 'comprador'. En su lugar, sólo recién ahora está emergiendo una burguesía...,"42.

De manera similar, Walter Rodney ha estudiado el impacto de la expansión capitalista en el desarrollo-subdesarrollo de Africa en gene$\mathrm{ral}^{43}$, mientras que Colin Leys ha aplicado la perspectiva de la dependencia al análisis del desarrollo económico y político de Kenya ${ }^{44}$.

Immanuel Wallerstein, por otra parte, ha argumentado que el nivel correcto de análisis para el estudio de la temática del imperialismo y el subdesarrollo es el "nivel mundial"45. De allí que para Wallerstein el

${ }^{40}$ Samir Amin, Neo-Colonialism in West Africa (Middlesex, England: Penguin Books, 1973), p. XIV.

En otro trabajo, Amin ha criticado las teorías del subdesarrollo existentes, afirmando que el crecimiento económico es un proceso desigual, $y$ ha analizado la desigualdad de la especialización internacional y las consecucncias de los nujos transnacionales de capital para la periferia y los centros. Ver Samir Amin, Accumulation on a World Scale: A critique of the Theory of Underdevelopment, dos volumenes (New York; Monthly Review Press, 1974).

1 Ibid., p. 274.

${ }^{42}$ Ibid., p. ix.

${ }^{43}$ WaLter Rodney, How Europe Underdeveloped Africa (Washington DC.: Howard University Press, 1974).

${ }^{4}$ Colin LEYs, Underdevelopment in Kenya, The Political Economy of Neo-Colonialism (London: Heinemann, 1975).

${ }^{45} \mathrm{Ver}$ Immanuel Wallerstein, "The Rise and Future Demise of the World Capitalist System: Concepts for Comparative Analysis", Comparative Studies in Society and History, vol. 16, $N^{\circ} 4,1974 ;$ I. Wallerstein, The Modern World System: Capitalist Agriculture and the 
capitalismo haya sido, desde un comienzo, "un asunto de la economia mundial y no de estados-naciones. Constituye un error de interpretación el afirmar que sólo en el siglo veinte el capitalismo se ha transformado en capitalismo mundial"16. Dada esta visión del problema, Wallerstein concluye que,

"Actualmente no existen sistemas socialistas en la economía-mundial, del mismo modo que no hay sistemas feudales, ya que existe un solo sistema-mundial. Es una economia mundial y es por definición de naturaleza capitalista. El socialismo implica la creación de un nuevo tipo de sistema-mundial, ni un imperio mundial redistributivo ni tampoco una economía-mundial capitalista, sino un gobierno-mundial socialis$\mathrm{ta}^{, 47}$.

Según un crítico, "la concepción de Wallerstein se caracteriza por su falta de visión histórica, que deriva de su identificación de prioridad analítica con prioridad histórica"48. El mismo crítico ha agregado que "Wallerstein ve al capitalismo desde la perspectiva de la circulación, como un sistema de mercado... Debido a que concibe el capitalismo desde el punto de vista de la circulación, le es imposible identificar las raíces de la lucha de clases"

Arghiri Emmanuel, por otro lado, ha concluido que el aumento de la desigualdad económica entre las naciones reside en un "intercambio desigual", una expresión que él usa para comunicar la idea que, en el mercado mundial, los países subdesarrollados están obligados a vender el producto de un número relativamente alto de horas de trabajo, para obtener a cambio el producto de una cantidad menor de horas de los países avanzados $^{50}$. En efecto, Emmanucl ha afirmado que el "intercambio desigual es el mecanismo de transferencia básico (de la plusvalía de un grupo de países a otro) y que, como tal, le permite a las naciones avanzadas

Origins of the European Economy in the 16 Century (New York: Academic Press, 1974); and 1. Wallerstein, "Dependence in an Interdepent World: The limited Possibilities of Transformation within the Capitalist World Economy", African Studies Review, vol. xvin, No 1, April 1974. p. 401 .

"Wallerstein, "The Rise and Future Demise of the World Capitalist System", Ibid.,

${ }^{47}$ Ibid., P. 415.

${ }^{48}$ Ira Genstein, "Theories of the World Economy and Imperialism" The Insurgent Sociologist, vol. VII, $\mathrm{N}^{\circ} 2$, Spring 1977, p. 10. En este mismo ensayo Gerstein también criticó los trabajos de $A$ min, Palloix y Poulantzas. Respecto a las respuestas de Amin y Wallerstein ver: Samir Amin, "Comment on Gerstein", The Insurgent Sociologist, vol. vil, N" 2, Spring 1977, pp. 99-103; e Immanuel Wailerstein, "How do we know Class Struggle when We see It?, Reply to Ira Gerstein", The Insurgent Sociologist, Vol, vil, $\mathrm{N}^{\circ} 2$, Spring 1977, pp. 104-106.

${ }^{40}$ Gerstein, ibid., p. 11.

${ }^{50}$ Arghikl Emmanuel, Unequal Exchange: A Study of the Imperialism of Trade (New York: Monthly Review Press, 1972). Charles Bettelheim criticó duramente el trabajo de Emmanuel, dando origen así a un vigoroso debate, parte del cual se incluye en los apéndices de! libro de Emmanuel. 
comenzar $y$ dar constantemente mayor dinamismo a aquella desigualdad de desarrollo que hace funcionar todos los otros mecanismos de explotación y explica totalmente el modo en que la riqueza se distribuye $e^{, 51}$.

Fuera del comercio internacional, otros analistas han investigado el papel de la inversión privada extranjera y las corporaciones multinacionales, como mecanismos vitales a través de los cuales se produce la transferencia de riquezas desde la periferia a los centros ${ }^{52}$, mientras que otros incluso mencionan los procesos de pago de la deuda externa, procesos que Eduardo Galeano ilustra de la siguiente mancra: "Primero, el imperialismo crea el paciente (por medio de la inversión directa), y luego construye el hospital dondc el paciente permanece atrapado y sin posibilidad de recuperarse (a través del pago de la deuda externa) ${ }^{p, 53}$.

Otro académico que ha escrito extensamente sobre la dependencia y el imperialismo es Johan Galtung. Según este analista, el imperialismo es una

"...relación de dominación entre colectividades, especialmente entre naciones. Es un tipo sofisticado de relación de dominación que penetra paises, basándose en cabezas de puente que el centro en la naciónCentro establece en el centro de la nación-Periférica, para el beneficio común de ambos... En breve, el imperialismo es un sistema que divide colectividades y vincula alguna de las partes entre sí en relaciones de armonia de intereses, $y$ otras partes en relaciones de disonancia de intereses o conflicto de inlereses"st.

Galtung no explica en forma clara cual es e! factor, o factores, que determina las relaciones de dominación-dependencia que él identifica con el imperialismo, o cuales son sus raíces históricas. Su análisis excesivamente mecánico-esquemático, lo ha llevado a examinar las asimetrias internacionales como si no hubiese diferencia cualitativa alguna en las relaciones centro-periferia bajo sistemas socio-económicos diferentes $s^{5 \delta}$. Más aún, la concepción de Galtung del imperialismo $-\mathrm{y}$ de lo que él también denomina "sub-imperialismo"- se asemeja nás a una politica nacional que a un proceso histórico y dinámico: imperialis-

${ }^{51}$ Ibid., p. 265.

${ }^{52}$ Paul Baran Y Paul Sweezy en su libro Monopoly Capital: An Essay on the American Economic and Social Order (New York: Monthly Review Press, 1966), demostraron que en el periodo posterior a la Segunda Guerra Mundial, y a diferencia de las décadas previas en que Estados Unidos "exportaba" capital, Estados Unidos comenzó a "importar" capital desde el exterior, agudizando asi la contradicción entre absorción y gencración de plusvalia.

${ }^{3}$ Euunado Galeano, "El Imperialismo Medio Siglo Después", Cuadernos de Marcha, $N^{\circ} 36$, Abril 1970, p. 67.

st Jolian Galtung, "A Structural Theory of Imperialism", Joumal of Peace Research. vol. 2,1971, p. 81.

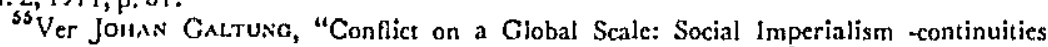
in the Structura! Theory of Imperialism", World Development, vol. 4, N $^{\circ}$ 3, March 1976. 
mo "es el problema de moldear otra sociedad, por medio de operaciones cabeza de puente efectivas, estableciendo relaciones de intercambio de carácter explotador..."ss; subimperialismo es un método de "construcción sobre estructuras ya existentes, haciendo uso del imperialismo de otro o de una aspiración en esa dirección ${ }^{, 57}$. Detrás de la mayor parte de los escritos de Galtung percibimos la falta del componente histórico y una preferencia manifiesta por un estructuralismo demasiado esquemático.

Finalmente, otras contribuciones interesantes durante esta última fase del descubrimiento de la perspectiva teórica de la dependencia en los círculos académicos de los centros, incluyen los trabajos de Norman Girvan, Susanne J. Bodenheimer, Keith Griffin y otros ${ }^{58}$. Al mismo tiempo, debemos mencionar que teóricos de la "nueva dependencia" tales como dos Santos, Cardoso, Quijano, Frank y otros han continuado produciendo trabajos refinados, en parte como respuesta a críticas, adentrándose en nuevas materias de investigación, y participando activamente en el creciente debate sobre la dependencia.

\section{LAS FUENTES METODOLOGICAS DE LA TEORIA DE LA DEPENDENCIA}

La perspectiva de la nueva dependencia tiene como raíz a los conceptos de contradicción y dialética, y de allí que haya podido presentar una visión más o menos dinámica y precisa de la realidad latinoamericana.

Según Cardoso, "desde las primeras proposiciones, el análisis dialéctico fue el punto de partida (de la teoría de la dependencia). Lo que importaba era el "movimiento", las luchas de clase, las redefiniciones de

${ }^{56}$ Ibid., pp. 156-157.

${ }^{57}$ Ibid., p. 163.

${ }^{58}$ Ver Norman Girvan "The Development of Dependency Economics in the Caribbean and Latin America: A Review and Comparison", Social and Economic studies, vol. 22, $N^{\circ}$ 1, March 1973: Susanne J. Bodenheimer (Jonas), "Dependency and Imperialism: The Roots of Latin American Underdevelopment" en K.T. Fann y Donald C. Hodges (eds.) Readings in U.S. Imperialism (Boston: Potter Sargent, 1971); y Keith .Griffin, Underdevelopment in Spanish America: An Interpretation (Cambridge, Mass.: MIT Press, 1969), y K. Griffin, "La Transmisión Internacional de la Desigualdad", Comercio Exterior, vol. 25, $N^{\circ} 8$, agosto de 1975. Sobre el tema de la dependencia cultural, las contribuciones más importantes han sido hechas por: Armand Mattelart, Agresión desde el Espacio: Cultura y Napalm en la Era de los Satélites (Valparaíso, Chile: Ediciones Universitarias de Valparaíso, 1972); Armand Mattelart y Ariel Dorfman, "How to Read Donald Duck", Liberation, vol. 19, $\mathrm{N}^{\circ}$ 3, 1975; Ariel Dorfman, "Chile: La Resistencia Cultural al Imperialismo", Casa de las Américas, vol. xvi, $N^{\circ}$ 98, septiembre-octubre 1976; Michele Matterlart y Mabel Piccini,

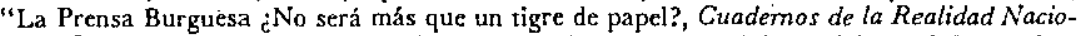
nal, $\mathrm{N}^{\circ}$ 16, abril 1973; Juan Corradi, "Cultural Dependence and the Sociology of Knowledge: The Latin American Case", International Journal of Contemporary Sociology, vol, viII, January 1971; Cristián d'Espinay Lalive, "Cultura y Dependencia en América Latina", Cuadernos de la Realidad Nacional, $\mathrm{N}^{\mathrm{a}} 7$, marzo 1971; y Fernando Reyes Matta (ed.), La. Información en el Nuevo Orden Intemacional (México: Instituto Latinoamericano de Estu-. dios 'Transnacionales, 1977). 
interés y las alianzas políticas que mantenian las estructuras al mismo tiempo que abrían la posibilidad de su transformación. Las estructuras se consideraban como relaciones de contradicción, y por lo tanto dinámicas $^{259}$.

Muy por el contrario, los estudios ortodojos de los fenómenos sociales, económicos y políticos en los países subdesarrollados, así como en otros lugares, han tendido a enfatizar lo permanente y lo estático. Teorias convencionales en los campos de la sociología y ciencia política, tales como el estructural-funcionalismo, la teoría de sistemas, y la teoría de comunicaciones han pretendido estar libre de elementos ideológicos al concentrarse en formas, funciones, estructuras y sistemas, ignorando $\rightarrow$ no enfatizando- la dialéctica y la historia.

La premisa básica de muchas de estas teorías es que la sociedad funciona -o por lo menos "debería" funcionar- como un sistema coherente, homogéneo y auto-regulado. Una "racionalidad" inherente en estos modelos permite el descubrimiento de condiciones propicias para la absorción de tensiones y desequilibrios amenazantes.

Muchos trabajos influenciados por el concepto de "equilibrio" han presentado a los países subdesarrollados - -como dijimos antes- como "sociedades dualistas" con campos feudales y ciudades capitalistas. Ya que se considera que las zonas agrarias han permanecido en el feudalismo debido al aislamiento de las fuerzas del capitalismo, la receta prescribe la penetración capitalista del campo. El desarrollo deberá fluir desde Estados Unidos (el centro hegemónico) a los centros urbanos nacionales, desde estas metrópolis a las ciudades comerciales regionales, y de estos últimos centros a sus respectivas periferias. Una buena ilustración es la concepción de Eisenstadt sobre la "modernización" como

"...el proceso de cambio hacia aquellos tipos de sistemas sociales, económicos y políticos que se han desarrollado en Europa Occidental y América del Norte desde el siglo diecisiete al diecinueve y que se han esparcido a otros países europeos y en el siglo diecinueve y veinte a Sudamérica, Asia y Africa"60.

El énfasis de estos modelos en los conceptos de equilibrio, estabilidad $y$ cohesión social se comprueba en su insistencia en el papel de las "clases medias" que se supone juegan un rol equilibrante de suma importancia en la sociedad.

Más importante aún, los modelos de equilibrio - al contrario de la teoría de la dependencia - tienden a negar las diferencias, transiciones, contradicciones y conflictos como fuerzas sociales valiosas. En efecto, la reivindicación del conflicto, desequilibrio, dialéctica $y$ de los compromisos

\footnotetext{
${ }^{39}$ Fernando H. Cardoso, "The Consumption of Dependency Theory in the United States", op. cit., p. 14.

${ }^{60}$ S.N. Eisenstadt, Modemization: Protest and Change (Englewood Cliffs, N.Y.: Prentice-Hall, 1966), p. 1.
} 
éticos se caracteriza en términos de desviaciones, disfunciones, y patologías.

Por supuesto, algunos sociólogos y antropólogos modernos han atribuido un propósito constructivo al conflicto (ej., Georg Simmel, Ralf Dahrendorf), pero sólo en la medida en que ayuda a establecer límites de grupos, fortalezca la conciencia de integración social, construcción de comunidad, $y / o$ evolución política $y$ económica. Al mismo tiempo, hay algunos académicos que, aunque no utilizan mayormente el concepto de "equilibrio", explican el subdesarrollo en términos de: "condiciones demográficas desfavorables" (A. Sauvy, Jacob Viner, Francois Perroux, Gerald Meier, Robert Baldwin); "posición desfavorable en lo que respecta a recursos naturales" (Jacob Viner, H. Myint); "falta de habilidad empresarial o mala calidad de la fuerza de trabajo" (David Mac Clelland, Jacob Viner); "falta o escasez de capital" (W. Arthur Lewis, Jacob Viner, A. Sauvy); "el círculo vicioso de la pobreza" (Ragnar Nurkse, Richard T. Gill, Bruno Knall); "inhabilidad para llegar a condiciones propicias para el 'despegue', 'el gran empuje, o el 'esfuerzo mínimo crítico'" (W.W. Rostow, Colin Clark, P. Rosenstein-Rodan, H. Leibeinstein); $y$ ' el "comercio exterior y otros factores 'externos' " (Raúl Prebisch, Gunnar Myrdal, Arthur Lewis, Francois Perroux).

Como vimos antes, la perspectiva teórica de la nueva dependencia y del subdesarrollo también constituye un capítulo heterogéneo de la economía política; pero, la aproximación metodológica es la misma: la dialéctica-histórica. Como dijera Tamas Szentes,

"Debates, divergencias de opiniones y, a menudo, juicios de valor y perspectivas contradictorias lo caracterizan (al análisis dialécticohistórico). Sin embargo, a diferencia de las teorías ortodojas, explica el fenómeno del subdesarrollo económico, las perspectivas de su erradicación y las interrogantes concretas del desarrollo futuro, siempre en relación a la historia, dentro de un cuadro de interrelaciones históricas, concentrándose en las principales fuerzas impulsoras del desarrollo social y económico, y analizando los fenómenos y sus causas como interdependencias dialécticas" 61 .

En otras palabras, aunque algunas interpretaciones convencionales del subdesarrollo no se basan exclusivamente en el concepto de "equilibrio", su carácter no-dialéctico las diferencian de la perspectiva teórica de la nueva dependencia. Implícita o explícitamente -afirma Cardoso- la "fuente metodológica (de la teoría de la dependencia) es la dialéctica" $" 62$.

La perspectiva de la dependencia va más allá del estado-nación como el único nivel y unidad de análisis, vinculando clases, sectores, naciones

${ }^{6}$ Tamas Szentes, Interpretations of Economic Underdevelopment (Budapest: Center for Afro-Asian Research of the Hungarian Academy of Sciences, 1968), p. 7.

${ }^{62}$ Fernando H. Cardoso, "Notas sobre el Estado Actual de los Estudios de la Dependencia", en Sergio Bagú y otros, Problemas del Subdesarrallo Latinoamericano (México, D.F.: Editorial Nuestro Tiempo, 1973), p. 99. 
y regiones de una manera verdaderamente transnacional. Estas características de la nueva teoría de la dependencia, deriva de su metodología, facilitando percepciones que las teorías ortodojas desatienden, o simplemente ignoran, acerca de la explotación internacional y doméstica, de afinidades estructurales de sectores sociales a través de fronteras estatales, etc. Octavio Ianni describió esta característica de la teoría de la dependencia de la siguiente manera:

"...la dialéctica imperialismo-dependencia no se reduce ni termina en las relaciones entre países o estados. Este es solamente un nivel de manifestación del capitalismo. Para entender la verdadera naturaleza de la dialéctica imperialismo-dependencia, es necesario llevar el análisis más allá. Entonces pasamos al ámbito de las relaciones sociales de producción" 63.

Finalmente, la metodología histórico-dialéctica de la dependencia -a diferencia del "estructuralismo-esquemático" y del "empiricismo anti-histórico" - se concentra en el estudio histórico de las relaciones estructurales mientras que, a la vez, reproduce teóricamente las interacciones dialécticas que existe entre conceptos y práctica ${ }^{64}$.

En resumen, la dialéctica le da al enfoque de la dependencia un caracter dinámico, que enseña que el entendimiento del subdesarrollo requiere un conocimiento del imperialismo, desde una perspectiva que apunte a identificar las contradicciones que surgen como resultado del proceso mismo de desarrollo capitalista.

\section{EL DEBATE SOBRE LA DEPENDENGIA: ALguNOS PROBLEMAS CLAVES}

El enfoque de la dependencia ha sido, particularmente en años recientes, objeto de múltiples críticas desde la derecha y la izquierda. Ya que muchas de las críticas, y críticos, coinciden, hemos estimado conveniente -para propósitos de ànálisis- agruparlas en nueve principales puntos o problemas: a) el término dependencia carece de la necesaria especificidad como para ser operacional, b) los teóricos de la dependencia conceptualizan y estudian la dependencia bajo el capitalismo, pero no discuten la dependencia en sistemas socialistas, c) los escritos sobre dependencia tienden a presentar esquemas mecánicos en que factores "externos" en vez de "internos" son los determinantes, d) los teóricos de la dependencia ignoran las clases sociales y la lucha de clases, e) la teoría de la dependencia pretende reemplazar las concepciones marxis-

${ }^{63}$ Octavio IanNi "La Dependencia Estructural", en A.M. Frasinetti y G. Boils (cds.), op. cit., pp. 141-142.

"Fernando H. Cardoso, "Notas Sobre el Estado Actual de los Estudios de la Dependencia", op. cit., p. 104. 
tas y leninistas del imperialismo, f) la teoría de la dependencia es de carácter nacionalista y propone un desarrollo capitalista autónomo en vez de estrategias para llegar al socialismo, g) algunos analistas presentan a las estructuras de la dependencia como estáticas y persistentes en vez de dinámicas, h) algunos estudiosos de la dependencia confunden los conceptos marxistas de "proceso de circulación" con "proceso de producción", e i) la teoría de la dependencia carece de "objetividad" académica y es de naturaleza ideológica.

a) El término dependencia carece de un contenido específico como para ser operacional.

Esta crítica ha sido formulada especialmente por académicos de los países avanzados algunos de los cuales -incluyendo a Philip O'Brien, David Ray, y Robert Packenham - argumentan que existe una falta de precisión, de cláridad conceptual en las propiedades o relaciones específicas que caracterizan el término "dependencia",65."Algunos académicos, a manera de solución, han procedido a cuantificar y "probar" la teoría de la dependencia; como si sólo el medir constituyese la condición necesaria y suficiente para el logro de precisión conceptual. En estos "test" de la dependencia, afirma Cardoso,

"...en vez de realizar un análisis dialéctico de procesos históricos, concibiéndolos como el resultado de luchas entre clases y grupos que definen sus intereses y valores en el proceso de expansión de un modo de producción, la historia se formaliza; las contribuciones particulares que estos análisis de la dependencia podrian hacer desde un punto de vista metodológico (es decir, la idea de contradicción), se extirpa. La ambigüedad, las contradicciones, y los "quiebres" más o menos abruptos en

${ }^{65}$ Ver Philip O'Brien, "Dependency: The New Nationalism?", Latin American Reviez of Books, vol. t, 1973, pp. 35-41; Sanjanya Lall, "Is 'Dependency' a Useful concept in Analyzing Underdevelopment?", World Development, vol. 3, November 1975, pp: 799810 , David Ray, op. cit., Robert Packenham, op. cit.

"Ver, por ejemplo, Robert R. Kaufman, Harry I. Chernotsky, y Daniel S. Geller, "A Preliminary Test of the Theory of Dependency", Comparative Politics, vol. 7, $\mathrm{N}^{\circ} \cdot 3$, April 1975; Christopher Chase-Dunn, "The. Effects of International Econornic Dependency on Development and Inequality: A Cross-National Siudy", American Sociological Review, vol. 40, December 1975; Patrik J.Mc Gowan "Economic Dependence and Economic Performance in Black Africa", Journol of Modem African Studies, vol. 14, March 1976; Patrick J. McGowan y Dale L. Smith, "Economic Dependency in Black Africa: an analysis of Competing Theories" Intemational Organization, vol. 32, $\mathrm{N}^{\circ} 1$, Winter 1978; W. Ladd Hollist y Thomas H. Johnson, Testing Dependency Explanations of International Cleavages: United States -Latin American Relations, trabajo presentado al Congreso de la "International Studies Association" (1977), St. Louis, Missouri, March 16-20, 1977. 
la realidad son reducidos a "dimensiones operacionales" que, por definición, son exclusivamente estáticas",67.

Aunque no rechazamos toda aproximación cuantitativa al tema de la dependencia — sólo aquellas de carácter estático realizadas hasta ahora- estamos de acuerdo con Cardoso cuando difiere con la idea de que para mejorar la calidad del análisis.

"...la teoría de la dependencia debía ser formalizada para que, después de probar las hipótesis derivadas de esta formalización - uno pudiese aventurarse en el mundo blandiendo la bandera del porcentaje de variación explicado por cada factor dentro de la situación de dependencia. En vez de pedir análisis dentro del marco del estructural- funcionalismo empiricista, sería mejor solicitar un mejoramiento de la calidad de los análisis histórico-estructurales",68.

Los estudios cuantitativos de la dependencia pasan por alto el hecho que la dependencia no es sólo un nuevo concepto, sino que también un marco teórico de análisis vinculado a la teoría del imperialismo.

Según Duvall, "la intención del término dependencia es connotar un 'marco' general en vez de un 'conjunto de información' precisa. La acusación de que la dependencia no se refiere de manera exacta a un concepto claro, y no tiene un referente empírico preciso no es una crítica de mucha relevancia a esta tradición ${ }^{169}$.

En forma similar, James Caporaso ha declarado que los teóricos de la dependencia no han definido explícitamente este último término, entre otras razones, porque su significado se entendía bien en América Latina, donde había surgido, y debido a la "negativa por parte de analistas de la dependencia de situar el concepto de dependencia fuera de sú contexto histórico elevándolo al status de un concepto abstracto" $y$, finalmente, porque "esa palabra puede funcionar como una eliqueta sinóptica para un cuerpo de teoria", (nuestro énfasis).

\footnotetext{
${ }^{67}$ Fernando H. Cardoso, "The Consumption of Dependency Theory in the United States", op. cit., p. 15.

${ }^{69}$ Ibid, p. 21.

${ }^{69}$ Raymond D. Duvall, "Dependence and Dependencia Theory: Notes Toward Precision of Concept and Argument", International Organization, vol. 32, $\mathrm{N}^{\circ} 1$, Winter 1978, p. 57.

${ }^{70}$ Caporaso, op. cit., p. 22.

Aunque estamos de acuerdo con Caporaso y Duvall cuando sostienen que el término "dependencia" es mucho más que un simple nuevo concepto conviene destacar que, de todas maneras, el término es muy concreto y preciso. Cualquiera buena teoría en las ciencias sociales debe referirse a abstracciones, pero como reflejos de la rèalidad. En este sentido, la dependencia es un concepto abstracto $\%$ a la vez, un fiel refejo de la realidad histórica. Por lo tanto, dicho término, no es menọs preciso que conceptos tales como, por ejemplo, "utilidad", "productividad marginal" o "equilibrio de poder".
} 
De hecho, cualquier repaso rápido de definiciones sobre dependencia revela que es más bien un marco teórico que una propiedad variable de países, grupos o instituciones.

Comenzando con Lenin podemos observar lo siguiente:

"...relaciones de esta clase (depedencia) han existido siempre entre estados grandes y pequeños, pero en la época del imperialismo capitalista se transforman en un sisiema general, formando parte de la suma total de las relaciones de 'división del mundo', tornándose en vínculos en la cadena de operaciones del capital financiero mundial ${ }^{171}$

Por otra parte, la bien conocida definición de Theotonio dos Santos dice así:

"Por dependencia entendemos una situación condicionante, en la cual un cierto grupo de paises tiene su economia condicionada por el desarrollo y expansión de otra economía a la cual la propia está sometida. La relación de interdependencia entre dos o más economías... asume la forma de dependencia cuando algunos paises... pueden expandirse y auto-impulsarse, en tanto que otros países. .. sólo lo pueden hacer como reflejo de esa expansión, que puede actuar positiva $y / 0$ negativamente sobre su desarrollo inmediato" ${ }^{, 72}$, (enfasis nuestro).

En otro trabajo dos Santos ha reiterado quc,

"La dependencia no es una relación en que una economía nacional está sometida a una economía externa, sino más bien una relaciỏn básica que configura y condiciona las cstructuras internas de las regiones dominadas o dependientes. La dependencia implica una situación económica, social y política en que la estructura de una sociedad está condicionada por las necesidades, acciones, e intereses de otras naciones dominantes",73.

Por último, Cardoso se ha referido a la dependencia del siguiente modo:

"...la dependencia, tal como la caracterizamos, no es más que la expresión política en la periferia del modo de producción capitalista cuando este modo pasa a expandirse a nivel internacional"74.

"Lenin, Imperialism, The Highest Stage of Capitalism, op. cit., p. 103.

${ }_{72}^{2}$ Dos Santos, Dependencia y Cambio Social, op. cit, p. 4.4.

${ }^{73}$ Dos Santos, "Brazil: The Origins of a Crisis", op. cit., p. 416.

"Fernando Henrique Carmoso, "Teoria de la Dependencia" o Analisis de Sizuaciones Concretas de Dependencia?", Reuista Latinoamericana de Ciencia Politica, vol, 1, diciembre 1970, p. 406. 
Hechas estas delimitaciones, el término "dependencia" es, según Duvall, aún muy significativo y útil, "porque su connotación de contexto, de marco de referencia, es muy claro y poco ambiguo... las contribuciones al conocimiento que aporta la teoría de la dependencia son acerca de aspectos de tales situaciones" ${ }^{\prime 75}$.

b) Los teóricos de la dependencia conceptualizan y estudian la dependencia bajo el capitalismo pero no discuten la dependencia bajo el socialismo.

Esta crítica es, en cierto modo, un corolario de la crítica precedente a la teoria de la dependencia. Lo que ha sucedido es que,

"...debido a que los científicos empiricistas han sido generalmente culpables de ignorar cl grado de precisión de significado que efectivamente han provisto los teóricos de la dependencia para el concepto de dependencia... los primeros han partido de significados de sentido común del término, y han causado la impresión de que reglas de medición desarrolladas en concordancia con esos significados es lo único que importa... El resultado es una distorsión del significado primario del término tal como aparece en la teoría de la dependencia" ${ }^{976}$.

Académicos tales como Ray, Packenham y otros, han hecho precisamente eso al definir la dependencia principalmente en términos de poder y restricciones a la autonomia nacional, y al concentrarse en indicadores tales como flujos de comercio, inversión de capital extranjero, ayuda exterior; etc., para determinar cuantitativamente el "grado de dependencia" que experimenta una determinada nación. Evidentemente, después que el concepto de dependencia es depurado de toda relación con análisis de clases y de modos de producción, es lógico que pueda ser aplicado a las relaciones entre estados socialistas. Por supuesto, esta variación no es lo que los teóricos de la nueva dependencia entienden por el término "dependencia".

En todo caso, algunos comentaristas de la dependencia piensan, por ejemplo, que Cuba debería ser incluida en la lista de países dependientes debido a su "manifiesta y profunda dependencia frente a la U.R.S.S." Este argumento se apoya en datos sobre transferencia de armamentos $y$ asistencia económica soviética a Cuba, fuera de cifras sobre el gran volumen de intercambio comercial que existe entre los dos paises.

Según Richard Fagen, "sin lugar a dudas que existe una situación de vulnerabilidad cuando un país más pequeño y pobre está vinculado internacionalmente a un proveedor o mercado predominante, o cuando

\footnotetext{
${ }^{75}$ Duvalt, op. cit., p. 57.

76 Ibid., P. 59.

${ }^{77}$ PACKENHAM, op. cit., p. 35.
} 
puede ofrecer solamente una o dos mercaderías para la exportación". Pero, Fagen ha indicado,

"...la vulnerabilidad no es el único componente de una situación de dependencia, y ciertamente no todo lo que significa la dependencia... los lazos Cuba-Unión Soviética constituyen un caso de 'relaciones de poder asimétricas' que denotan 'dependencia' en el sentido restringido de confiabilidad y por tanto (potencialmente) vulnerabilidad. Pero las relaciones existentes no condicionan la economia y sociedad de la isla en el sentido que se deriva de la perspectiva de la dependencia sobre el problema del desarrollo. En efecto, la transformación socialista de la economía cubana ha liberado a personas y fuerzas productivas de la condición estructural de dependencia, creando la atmósfera propicia para resolver la mayoria de los problemas básicos que enfrenta la sociedad",78

E! caso cubano, a diferencia de lo que algunos académicos piensan, constituye -en la opinión de muchos- una buena ilustración del por qué los teóricos de la nueva dependencia en la década del 60, afirmaban que la reestructuración de la economía politica doméstica, era un paso indispensable para superar los fenómenos de la dependencia y el subdesarrollo.

c) Los escritos sobre dependencia tienden a presentar esquemas mecáni. cos en que aspectos "externos" en vez de "internos" son determinantes.

José Luis de Imaz ha criticado el enfoque de la dependencia argumentando - entre otras cosas - que el concepto de dependencia pretende explicar demasiado, asignando la mayor parte de la culpa por el subdesarrollo latinoamericano a factores "externos"79. Sorprendentemente, a pesar de la cvidencia masiva de la literatura sobre la nueva dependencia que demuestra todo lo contrario, este punto de vista está muy difundido entre algunos críticos de la dependencia. Por ejemplo, Arnold Van Nickerk, Guy Erb y otros apoyan la idea de que los que han contribuido al desarrollo de la teoria de la dependencia, consideran que la dependencia es un problema de carácter "externo". Por el contrario, sin embargo, los teóricos de la dependencia visualizan la dependencia desde una perspectiva histórico-estructural que sobrepasa la distinción analítica entre factores internos y externos que tiende a ocultar la

\footnotetext{
${ }^{78}$ RICHARD R. FAGEN, "A Funny Thing Happened on the Way to the Markel: Thoughts on Extending Dependency Ideas", International Organization, vol. 32, $\mathrm{N}^{\circ} 1$, Winter 1978, p. 297. Otro ensayo que rechaza el argumento de la "dependericia-bajo-el socialismo" es un trabajo de Guy J. Gilbert, titulado "Socialism and Dependency", Latin American Perspectives, vol. $\mathrm{I}, \mathrm{N}^{\circ} 1, \mathrm{~S}$ pring 1974 .

J.L. DE IMAZ, op. cit., p. 50.
} 
unidad estructural que existe entre ellos. La concepción dialéctica de la dependencia, por lo tanto, supera las dicotomías "externo-interno", "desarrollo-subdesarrollo", relacionándolas en una sola estructura mundial: el sistema capitalista internacional. Como dijera Octavio Ianni: "la dialéctica imperialismo-dependencia no se reduce ni termina en las relaciones entre países o estados. Este es solamente un nivel de manifestación del capitalismo. Para comprender la verdadera naturaleza de la dialéctica imperialismo-dependencia es necesario llevar el análisis más allá. Enionces pasamos al campo de las relaciones sociales de producción" $8 \mathrm{I}$ (énfasis nuestro)

De manera similar, André Gunder Frank ha afirmado que,

"...si el subdesarrollo fuese sólo una condición "externa" impuesta desde afuera y expresada principalmente en una fuga de capital por medio del comercio y la ayuda extcrior, como algunos dicen, entonces las simples soluciones "nacionalistas" criticadas en este libro podrían considerarse adecuadas $\$ 82$.

Frank ha insistido en que "el problema es uno de subdesarrollo al nivel nacional y local, a pesar que fue creado y sigue siendo agravado por la estructura y desarrollo de la economia capitalista mundial" ${ }^{\prime 83}$.

En un tono parecido, Theotonio dos Santos indicó que "la dominación "externa" es impracticable por principio. Sólo es posible la dominación cuando encuentra respaldo en los sectores nacionales que se benefician de ella",84.

En resumen, la preocupación de los teóricos de la dependencia con las clases sociales, la atención prestada al problema del subdesarrollo y al "colonialismo interno", y el énfasis colocado en los modos de producción existente y las estructuras específicas de la dependencia, --todo esto dentro de un marco dialéctico - debilita considerablemente la afirmación de que los que desarrollaron dicha teoría entienden a la dependencia como un fenómeno "externo".

d) Los teóricos de la dependencia ignoran las clases sociales y los conflictos de clase.

Esta crítica, dirigida especialmente a Gunder Frank, ha surgido predominantemente de sectores de izquierda que afirman que los principales analistas de la dependencia han descuidado, e incluso omitido, el estudio

\footnotetext{
${ }^{80}$ Ver Arnold Van Niekerk, "La Pendiente de la Dependencia: Una yisión desde afuera", Estudios Internacionales, vol. v, No 18, abril-junio 1972, pp. 29-40; Guy Ern, op. cit..

IIINN1, op. cit., pp. 141-142.

${ }^{82}$ ANDRE GUNDER FHANK, Capitalism and Underdevelopment in Latin American: Historical Studies of Chile and Brazil (New York: Monthly Review Press, 1969). pp. xxii, y xxi.

${ }^{B 3}$ Loc. cit.

${ }^{84}$ dos SAntos, Dependencia y Cambiu Social, op. cit., p. 49.
} 
de problemas de clase tanto en los países subdesarrollados como en los desarrollados. Según Agustín Cueva, por ejemplo, "estos autores reemplazan explotación y lucha de clases por un sistema indeterminado de contradicciones nacionales y regionales que presenta serios problemas desde un punto de vista teórico... En general, es el análisis de clases y conflictos de clases que constituye el Talón de Aquiles de la teoría de la dependencia" ${ }^{\prime 85}$. Por otro lado, Fernández y Ocampo, en un artículo en que defienden la aplicación de la tesis Maoista de la "nueva democracia" a la realidad latinoamericana, acusan a los analistas de la dependencia de enfatizar excesivamente el problema de la lucha de clases en vez de la cuestión del imperialismo: "La creencia en el predominio del capital industrial le permite a los dependentistas considerar la lucha contra el imperialismo como secundaria a la lucha de clases y la batalla contra el capitalismo, ${ }^{, 86}$.

Aunque Frank ha admitido un cierto descuido de interrogantes de clase en su análisis del "desarrollo de! subdesarrollo", parecería que la mayor parte de los teóricos de la dependencia - incluyendo al mismo Frank- consideran el conflicto de clases y el análisis de clase como un componente vital de la llamada "teoría de la dependencia". Frank visualizó el problema de la siguiente manera:

"El esfuerzo por describir la estructura colonial metrópolis-satélite y el desarrollo del capitalismo, me ha conducido a dedicar poca atención específica a su estructura de clase y desarrollo. Esto no significa que este análisis colonial pretenda sustituir al análisis de clase. Por el contrario, el análisis colonial pretende complementar el análisis de clase y descubrir y enfatizar aspectos de la estructura de clases en estos países subdesarrollados que muchas veces han quedado poco claros" 87 .

Frank expandió sus comentarios sobre el problema de clase y sobre otros puntos, en un ensayo de respuesta a sus críticos titulado, en forma muy simbólica, "La Dependencia está Muerta, Viva La Dependencia y la Lucha de Clases, ${ }^{\text {,88 }}$, y en su libro Lumpenburguesía: Lumpendesarrollo (1972), donde afirmara que:

"...es más importante definir y entender el subdesarrollo en términos de clase... Sin embargo,... el subdesarrollo en una región dependiente como América Latina no puede ser entendido excepto como el producto de una política burguesa formulada en respuesta a intereses de clase

\footnotetext{
${ }^{86}$ Acustin Cueva, "A Summary of Problems and Perspectives of Dependency Theory", Latin American Perspectives, vol. III, N ${ }^{\circ}$, Fall 1976, pp. 13-14.

${ }^{86}$ RaÚl FERNANDEZ y JosE F. OCAMPO, "The Latin American Revolution: $A$ Theory of Imperiailism, Not Dependence", Latin American Perspectives, vol. 1, N 1, Spring 1974, p. 48.

${ }^{87}$ ANDRE Gunder Frank, Capitalism and Underdevelopment in Latin America, op. cit..p. p. xv.

"Ba ANdre Gunder Frank, "Dependence is Dead, Long Live Dependence", Latin American Perspectives, vol. I, N ${ }^{\circ}$ 1, Spring 1974, pp. 87-106.
} 
y connictos de clase que son a su vez determinados por la dependencia del satélite latinoamericano con respecto a la metrópolis colonialista e imperialista, ${ }^{, 89}$.

En todo caso, el énfasis puesto por la mayoría de los analistas de la dependencia sobre el limitado papel de la llamada "burguesía nacional". en el desarrollo de América Latina, y su creencia, con notables excepciones, en una transformación social conducida por el proletariado como la única respuesta real a la dependencia, demuestra plenamente el rol crítico que juega el análisis de clase en la perspectiva teórica de la dependencia ${ }^{90}$. La afirmación que los teóricos de la nueva dependencia no enfatizan problemas de clase parece calzar mejor con las corrientes "ortodojas" de la dependencia. Según Harding:

"Teóricos burgueses de la dependencia naturalmente consideran que la contradicción básica es entre dependencia y desarrollo nacional, no entrc trabajadores versus los dueños de los medios de producción. Aquellos tienden a visualizar a los trabajadores como elementos cooptados y manipulados pasivamente, y a considerar a los intelectuales radicalizados como la única fuerza capaz de combatir la dependencia en forma efectiva", ${ }^{\prime \prime 1}$.

e) La teoría de la dependencia pretende reemplazar a la teoria marxistaleninista del imperialismo.

Esta crítica, proveniente principalmente de sectores de izquierda, se relaciona en cierto modo con la crítica anterior sobre el conflicto de clases, $y$ ha sido dirigida primordialmente a Frank y a Cardoso.

Según Fernández y Ocampo, por ejemplo, la teoría de la dependencia es, primero, "una revisión del Marxismo", segundo, "no explica la naturaleza y persistencia del subdesarrollo en América Latina" $y$, finalmente, "ignora la teoría del imperialismo como guía para la revolución en los países atrasados de América Latinaa", José F. Ocampo, en otro trabajo, acusó específicamente a Frank de afirmar que "el imperialismo no existe y que las alianzas no constituyen un principio básico en la política marxista",

\footnotetext{
${ }^{80}$ Andre Gunder Frank, Lumpenbourgeoisie: Lumpendevelopment, Dependence, Class and Politics in Latin American (New York: Monthly Review Press, 1972), p. 1.

${ }^{90}$ Sobre este punto ver también Rodolfo Stavenhagen, "Siete Tesis Equivocadas sobre América Latina" (especialmente la tesis $\mathrm{N}^{\circ} 4$ y 5 ) en F.H. Cardoso y F. Weffort (eds.), op. (it., pp. 82-94; y Héctor Silva-Michelena, "Del Subdesarrollo al Socialismo: La Unica Estrategia" en Sergio Bagú y otros, Problemas del Subdesarrollo Latinoamericano, op. cit., pp. 169-195.

T. HARDING, op. cit., p. 9 .

${ }^{22}$ FeknANDEZ Y Ocampo, op. cit., p. 30.

${ }^{93}$ Jose F. Ocampo, "On What's New and What's Old in the Theory of Imperialism:
} A Reply to A Frank, the dependentistas, and the others", Latin American Perspectives, vol. II, $N^{\circ} 1$, Spring 1975, p. 33. 
Por otra parte, John Myer, refiriéndose a los escritos de Fernando H. Cardoso, ha declarado que:

"...muchas de las implicancias prácticas de la teoria de Cardoso se oscurecen por el carácter altamente abstracto de su discusión tcórica sobre la dependencia, y la naturaleza fundamentalmente anti-leninista de su teoría oculta por su usó constante de la terminología marxista y frecuentes referencias a las teorías políticas y económicas de Lenin" "94.

Parte de la confusión que prevalece en torno a la conexión dependencia-imperialismo, se origina de una carencia de claridad en el lenguaje por parte de algunos teóricos de la dependencia:

"Los nuevos analistas que usaban términos de dependencia a menudo no explicitaban la relación entre su teoría y la teoría marxista-leninista del imperialismo, y cuando intentaban hacerlo a veces distorsionaban la teoría marxista-leninista. Es1o condujo a considerable confusión con respecto a si los que utilizaban la terminologia de la dependencia eran efectivamente marxistas",95.

Sin embargo, con el desarrollo de la discusión sobre la dependencia y a la luz de las críticas, los teóricos de la nueva dependencia clarificaron o modificaron sus afirmaciones teóricas, declarando que la teoría de la dependencia se basaba en la metodología dialéctica, y sólo podia ser entendida en términos de la teoría del imperialismo.

Por' consiguiente', la afirmación de críticos tales como Fernández, Ocampo y Myer en el sentido que los teóricos de la dependencia han pretendido desplazar la interpretación marxista-leninista del imperialismo reemplazándole por la tcoría de la dependencia, parece ser infundada, Más aún, y sin desear asumir la defensa de ningún teórico de la dependencia en particular, 'muchas de las aseveraciones de 'estos criticos sobre el trabajo de Frank y Cardoso, por ejemplo, son generalmente distorsiones de los puntos de vista reales expresados por estos últimos ${ }^{96}$.

"John MYEk, "A Crown of Thorns: Cardoso and Counter-Revolution", Latin American Perspectives, vol, $11, N^{a}$ 1, Spring 1975, p. 53.

${ }^{\circ}$ Hardinc, op. cit., p. 5.

${ }^{96}$ Como dijéramos anteriormente, la intención de Fernández y Ocampo es, como ellos mismos reconocen, aplicar la tesis Maoista de la "nueva democracia" como guía para la "revolución latinoamericana", y quizás esta es la razón por la cụal se-ven en la necesidad de distorsionar los escritos sobre la dependencia. Myer, por otra parte, realmente no acusa a Cardoso de pretender reemplazar a la teoria marxista-leninista del imperialismo por la teoria de la dependencia, pero afirusa que "Cardoso es muy pesimista acerca del papel revolucionario de la clase trabajadora", y que sus conclusiones prácticas generaies están diametralmente opuestas a las de Marx y Lenin, además de ser inconsistentes con la propia aserción de Cardoso en el sentido de que la dependencia es una contribución a "las luchas contra el imperialismo capitalista". Fernando H. Cardoso respondió a éstas y otras críticas en su ensayo, "O Inimigo de Papel", op. cit.; mientras que Gunder Frank hizo lo mismo en su "Depen- 
De cualquier manera, un examen cuidadoso de la literatura sobre la dependencia lleva a la conclusión que, según lo alli expresado, cl imperialismo y la dependencia están mutuamente, intimamente $y$ lógicamente relacionados. Cardoso, por ejemplo, en su trabajo "Notas Sobre el Estado Actual de los Estudios de la Dependencia", vincula muy explicitamente a la teoría de la dependencia con la metodología dialéctica en general y, más especificamente, con la teoría del imperialismo. En las palabras de Cardoso mismo, la leoría de la dependencia "no es una alternativa a la teoría del imperialismo sino un complemento de ésta (nuestro énfasis) ${ }^{97}$.

Refirièndose a la interrogante si la dependencia podría ser correctamente llamada una "teoría", Cardoso nuevamente explicitó la conexión dependencia-teoría del capitalismo:

"No creo que la categoría dependencia tenga el mismo status teórico que las categorías centrales de la teoría del capitalismo. La razón es obvia: no se puede concebir la dependencia sin los conceptos de plusvalia, expropiación, acumulación, etc. La idea de la dependencia adquiere significado dentro del marco teórico de la teoría marxista del capitalismo,"88 .

Al mismo tiempo, Cardoso admitió que efectivamente era posible pensar o "concebir una teoría de la dependencia, siempre y cuando esté inserta en el marco teórico más amplio de la teoría del capitalismo o la teoría del socialismo" ${ }^{\prime, 99}$.

Aunque Ocampo acusó a Frank de negar la existencia del imperialismo, Frank, paradójicamente, respondió argumentando que Fernández y Ocampo "ignoraban el rol de la burguesía en la historia y arbitrariamente atribuían el atraso o subdesarrollo a causas externas, diciendo casi absolutamente nada respecto a la naturaleza contemporánea del imperialismo" (énfasis nuestro) ${ }^{100}$.

La importancia del imperialismo para Frank se refleja en la siguiente afirmación que él hiciese: "El imperialismo es ciertamente el principal enemigo de la humanidad hoy en día"101 . Según Frank, sin embargo, es necesario diferenciar entre el enemigo "principal" y el enemigo "inmediato". De alli que concluyese que $-y$ aquí reside un foco primordial de desacuerdo con Fernández y Ocampo- "la movilización

dence is Dead, Long Live Dependence and the Class Struggle", op. cit., y en su Lumpenbourgeoisie: Lumpendevelopment, op. cit.

${ }^{97}$ Cardooso, "Nolas Sobre el Estado Actual de los Estudios de la Dependencia", Op. cit., p. 108.

Ibid., p. 107.

${ }^{90}$ Loc. cit.

${ }^{100}$ Frank, "Dependence is Dead, Long Live Dependence and the Class Struggle", op. cit., p. 101.

${ }_{101}$ ANDré Gunder Frank, "Capitalist Underdevelopment or Socialist Revolution" en A.G. Frank, Latin America: Underdevelopment or Revolution, op. cit., p. 388. 
popular en contra del enemigo de clase inmediato al nivel nacional y local, produce un enfrentamiento más duro con el enemigo imperialista principal de lo que ocurriría mediante una movilización anti-imperialista directa" ${ }^{102}$. De todos modos, la importancia del imperialismo en el análisis de Frank es evidente, y en ninguno de sus escritos percibimos una intención expresa de desplazar la teoría del imperialismo en favor de otras interpretaciones teóricas.

Finalmente, la conexión orgánica imperialismo-dependencia ha sido destacada por varios otros académicos incluyendo a dos Santos, Quijano, Marini, e Ianni (quién a menudo habla de la "dialéctica imperialismo-dependencia"). En resumen, Cardoso parece haber estado en lo correcto cuando afirmó que los teóricos de la dependencia nunca pensaron en "substituir, criticar como no relevante, etc., la teoría del imperialismo ya sea en términos teóricos o en su análisis general",103.

\section{f) La teoría de la dependencia es de carácter ideológico nacionalista y propone un desarrollo capitalista autónomo en lugar de estrategias para construir el socialismo}

Este cargo, proveniente por lo general de círculos académicos de izquierda, ha sido dirigido principalmente a Cardoso y a analistas ortodojos de la dependencia tales como Helio Jaguaribe. Agustín Cueva ha sido cläro y categórico en su crítica, afirmando que "los exponentes de la teoría de la dependencia revelan un anhelo nostálgico por un desarrollo capitalista autónomo frustrado, que es precisamente lo que hace a la teoría de la dependencia tan nacionalista en su ideología"104. La afirmación de Cuevas es claramente injustificada cuando se refiere a la mayoría de los teóricos de la dependencia, incluso si uno considera la tesis de Cardoso sobre el "desarrollo dependiente-asociado".

Tomando Brasil como un estudio de caso, Cardoso observó que,

"Actualrnente, para la General Motors, Volkswagen, General Electric, o Sears Roebuck, el mercado latinoamericano sino el mercado particular de cada país donde esas compañías producen en América Latina, es la meta inmediata en términos de ganancia. Por lo tanto, al menos hasta cierto punto, un cierto tipo de inversión extranjera necesita alguna clase de prosperidad interna" ${ }^{\text {"105 }}$.

La internacionalización del mercado doméstico - ha sugerido Cardoso-- creará las condiciones para la continua prosperidad de una porción creciente de la sociedad brasilera. Cardoso ha declarado claramente que su

\footnotetext{
${ }^{102}$ Ibid., p. 371 .

${ }^{103}$ Cardoso, "O Inimigo de Papel", op. cit., p. 68.

${ }^{104}$ Cueva, op. cil., p. 13.

${ }^{105}$ CARDoso, "Dependency and Development in Latin America", op. cit., p. 90.
} 
tesis del "desarrollo dependiente-asociado" se contrapone con la tesis de Gunder Frank sobre el "desarrollo del subdesarrollo" ya que, a pesar de la dependencia, postula un tipo de desarrollo compatible con los intereses de las corporaciones transnacionales que podría extenderse en América Latina. La conclusión que se desprende de la tesis de Cardoso es que una transformación socialista no es la única respuesta o alternativa al subdesarrollo latinoamericano, ya que puede ocurrir un "tipo de desarrollo capitalista dependiente en sectores del Tercer Mundo integrados a nuevas formas de expansión monopólica" 106 .

Es necesario reconocer que Cardoso admite que, "a pesar del desa. rrollo económico interno, países vinculados al capitalismo internacional por ese tipo de lazos siguen siendo económicamente dependientes, en la medida en que la producción de bienes de producción (tecnología) esté concentrada en las economías capitalistas avanzadas (principalmente en EE.UU.)" (nuestro énfasis) ${ }^{107}$. Además, Cardoso ha señalado que este tipo de desarrollo dependiente implica un sinnúmero de serios costos sociales a los sectores populares.

Tomás Vasconi también ha sostenido que las naciones dependientes no están necesariamente condenadas a un subdesarrollo perpetuo. En breve, el desarrollo en un país dado - según Vasconi- no siempre está impedido por la existencia de dependencia. Por otro lado, el mismo autor ha sugerido que los países dependientes pueden llegar a romper sus vínculos de dependencia, pero sin necesariamente experimentar desarrollo. Vasconi ha insistido en que el problema de la dependencia requiere un análisis de factores internos y externos, dentro de la realidad específica de cada nación ${ }^{108}$.

Por el contrario, André Gunder Frank y otros, son de la opinión que "ningún país que ha estado firmemente vinculado a la metrópolis como satélite a través de su incorporación en el sistema capitalista mundial ha adquirido el rango de país económicamente desarrollado, excepto haciendo abandono del sistema capitalista"109.

Quizás las críticas a Cardoso pueden ser aplicadas más fácilmente a teóricos ortodojos de la dependencia como Helio Jaguaribe, quien concibe dos caminos hacia la autonomia y la independencia: uno reformista y el otro revolucionario. Ya que para Jaguaribe el socialismo no es la única solución a la dependencia, su alternativa predilecta es lo que él denomi-

${ }^{100}$ Ibid., p. 89.

${ }^{107}$ Ibid., p. 90.

${ }^{108}$ TomÁs VASCON1, "De la Dependencia como una categoria básica para el análisis del desarrollo latinoamericano", en Carlos Lessa y Tomás Vasconi (eds.) Hacia una Crítica de las Interpretaciones del Desarrollo Latinoamericano (Caracas: Universidad Central de Venezuela, 1969), pp. 34-51.

${ }^{100}$ Frank, Capitalism and Underdevelopment in Latin America, op, cit., p. 11. 
na "desarrollismo nacional", una estrategia basada en "diversas combinaciones de capitalismo nacional y capitalismo estatal" 110 .

g) Algunos analistas presentan a las estrucluras de la dependencin como estáticas y persistentes en lugar de dinámicas

Esta critica ha sido dirigida principalmente a Gunder Frank por otros teóricos de la dependencia tales como Theotonio dos Santos. Según dos Santos, parte del problema de Frank es su concepción errónea de la contradicción y la dialéctica, que ignora la continuidad y universalidad del cambio:

"De ahi se deriva el carácter estático en el sistema de Gunder Frank. Las contradicciones de América Latina son, para ell, las mismas desde su descubrimiento hasta hoy. Los cambios que han existido, y el mismo Frank admitc que son importantes, en su análisis aparecen como "irracionales" o mejor, como resultado de factores aleatorios... (Pero) si la estructura de nuestros paises es la misma y ha permanecido igual en todo este período, ¿Cómo se explican estos cambios que se han producido en América Latina?"'11.

De modo similar Fernando H. Cardoso ha escrito que,

"...la presunción de una "falta de dinamismo" estructural en las economias dependientes debido al imperialismo, malinterpreta las verdaderas formas de imperialismo económico y presenta un entendimiento político equivocado de la situación... Doy por contado que existen diferentes variedades de dependencia en América Latina, y que en algunas de ellas el desarrollo produce un cambio en las relaciones de poder internas, desplazando los vicjos grupos de poder oligárquicos y reforzando tipos más "modernos" de control político" "12.

La interpretación misma de dos Santos sobre la dependencia es dinámica y de carácter histórico. En su opinión, existen varios tipos de dependencia que pueden ser asociados con diferentes fases históricas: la dependencia colonial, la dependencia financiero-industrial y la dependencia lecnológico-industrial o nueva dependencia. En los períodos caracterizados por las dos primeras variantes de la dependencia, la producción en las

${ }^{10}$ Heuo Jaguaribe, Political Development: A General Theory and a Latin American Case Study (New York: Harper \& Row, 1973), p. 536.

111 oos Santos, Dependencia y Cambio Social, op. cit., p. 150.

112 Fernando H. Cardoso, "Dependency and Development in Latin America", op. cil., p. 94. 
regiones subdesarrolladas se orientaba hacia la exportación de bienes (oro, plata y productos tropicales durante la etapa "colonial"; minerales y bienes agrícolas en la fase "financiero industrial"). En otras palabras, la orientación de la producción estaba condicionada por la demanda que se originaba en los centros hegemónicos. En contraste, - sostiene dos Santos- en el tercer período de "nueva dependencia", que evolucionó después de la Segunda Guerra Mundial, -basado en la inversión por parte de empresas multinacionales---, la producción industrial comienza a ser condicionada de varias maneras por las exigencias del mercado internacional de bienes y capitales ${ }^{113}$.

Las críticas de dos Santos a los primeros trabajos de Frank fueron incorporadas a un estudio posterior de este último, titulado Lumpenburguesia: Lumpéndesarrollo (1972)"14, "que enfatiza la activa participación de clase "interna" en la determinación del proceso histórico $y$ algunas de sus variaciones entre paises"115.

\section{h) Algunos leóricos de la dependencia confunden los conceptos marxistas de "proceso de circulación" con "proceso de producción"}

Esta crítica ha sido hecha por académicos tales como Theotonio dos Santos, Ernesto Laclau, Agustin Cueva, Marta Harnecker, Marvin Sternberg, Kyle Steenland y otros ${ }^{116}$, en respuesta a errores en el trabajo inicial de André Gunder Frank.

Ernesto Laclau, por ejemplo, aunque ha aceptado la crítica a la tesis de las sociedades dualistas, rechazó la categorización por parte de Frank de la economía latinoamericana en el sentido de que habria sido capitalista desde tiempos coloniales. Según Laclau, con quien concordamos, Frank confundió los conceptos de "modo capitalista de producción" y "participación en un sistema capitalista mundial":

"La relación económica fundamental del capitalismo la constituye la venta de la fuerza de trabajo del trabajador libre, cuya necesaria precon-

${ }^{113}$ dos Santos, Dependencia y Cambio Social, op. cit., pp. 51-55. Ver también T. dos Santos, "El nuevo carácter de la Dependencia", Pensamiento Crítico, N N 43, 1973, pp. 60-73.

114 Frank, "Mia Cu!pa", Lumpenbourgeoisie: Lumperdevelopment, op. cit.

${ }^{115}$ Frank, "Dependence is Dead, Long Live Dependence and the Class Struggle", op. cit., $\mathrm{p}_{10} 97$.

${ }_{196}$ Ver Theotonio dos Santos, Dependencia y Cambio Social, op. cit.; Ernesto Laclau, "Feudalism and Capitalism in Latin Amcrica", New Left Review, N 67, May-June 1971; Agustin Cueva, op. cit.; Marta Harnecker, El Capital: Conceptos Fundamentales (Santiago de Chile: Editorial Universitaria, 1971), pp. 20-21; Marvin Siernberg, Dependency, Imperialism, and the Relations of Production", Latin American Perspectives, vol. 1, N ${ }^{\circ}$ 1, Spring 1974; y Kyle Steenland, "Notes on Feudalism and Capitalism in Chile and Latin America", Latin American Perspectives, vol, 11, $\mathrm{N}^{\circ} 1$, Spring 1975. 
dición es la pérdida, por parte del productor directo, de la propiedad de los medios de producción... Si ahora confrontamos la afirmación de Frank que los complejos socio-económicos de América Latina han sido capitalistas desde el período de la conquista... con la evidencia empirica disponible, debemos concluir que la tesis "capitalista" es indefendible. En regiones con densa población indigena -México, Perú, Bolivia o Guatemala- los productores directos no fueron despojados de su propiedad de los medios de producción, mientras que la coerción no-económica para maximizar varios sistemas de prestamiento de servicios... se intensificó progresivamente. En las plantaciones de las Indias Occidentales, la economía se basaba en un modo de producción esclavista, mientras que en las áreas mineras surgieron formas disfrazadas de esclavitud y otros tipos de trabajo forzado que no sc asemejaban en nada a la formación de un proletariado capitalista,177.

Steenland manifestó su acuerdo con el análisis de Laclau al escribir, en un estudio de caso sobre Chile, que:

"...aunque negamos que América Latina fuese predominantemente feudal y necesitase una etapa de desarrollo capitalista, cs necesario rechazar la aserción de Gunder Frank en el sentido que Chile (y América Lalina) ha sido capitalista desde mediados de $1500 .$. Un estudio de esas relaciones de producción revela que ciertamente no fueron capitalistas durante la mayor parte de la historia de Chile. En efecto, ellas se han caracterizado por una coerción extra-económica por parte de los latifundistas, la propiedad de algunos medios de producción por parte de la fuerza de trabajo agrícola, y una restricción del mercado interno que ha impedido el desarrollo del capitalismo" 118 .

Dos Santos también opinó que era erróneo concluir que porque la economía latinoamericana estuvo, durante el periodo colonial, dominada por el capital mercantil, que necesariamente se caracterizaba por un modo de producción capitalista. Según dos Santos, esto último tampoco significaba una justificación de lo que ćl considera la falsa tesis del carácter feudal de la economía latinoamericana ya que, a pesar de la existencia de modos de producción cercanos al fcudalismo, la totalidad de la economía apuntaba a la producción de mercancias y estaba dominada por el capital comercial financiero. Sugiriendo que quizás la economia latinoamericana era "pre-capitalista", dos Santos concluyó que "para comprender la realidad latinoamericana es necesario, pues, partir de los modos de producción precapitalistas de la fase colonial, bajo el dominio del capital mercantil y financiero" $" 119$.

${ }^{117}$ E. LACLAU, op. cit., p. 25, 30.

${ }^{118}$ STEENLAND, op. cit., p. 51.

${ }^{110}$ Dos SAntos, Dependencia y Cambio Social, op. cit., p. 152. 
Siguiendo la recomendación de que para producir teorias fructíferas en economía política es necesario pasar de un análisis del proceso de circulación a un análisis del proccso de producción, Cueva criticó a Frank de la siguiente manera: "para que la tesis de André Gunder Frank que América Latina ha sido capitalista desde la conquista española-portuguesa tenga sentido, sc debe abandonar la noción de Marx sobre el capitalismo haciéndola equivaler simplemente con la economia monetaria"120.

Por otra parte Sternberg declaró que el intento de Frank por probar que las relaciones de producción en América Latina han sido de naturaleza capitalista desde la conquista es innecesario e insuficiente:

"Es innecesario porque la existencia de modos de producción precapitalistas no excluye el desarrollo de la dependencia, y es insuficiente porque, si ello se probase, pondria la fecha del predominio capitalista en estos paises del. Tercer Mundo, en una fecha mucho anterior al logro de tal predominio - en la perspectiva de Marx y Dobb- dentro de las naciones de la metrópolis misma"12

Concentrándose en el problema de la coexistencia y predominio de dados modos de producción, Sternberg agregó que:

"Haciendo una lectura menos literal de la posición de Frank, es ciertamente posible y muy lógico afirmar que, junto con el surgimiento de relaciones capitalistas de producción en la metrópolis, ocurrió una expansión hacia y penetración de los satélites por dichas relaciones. Desde esta perspectiva, es sin duda verdadero que los satélites participaron en (o estuvieron sujetos a) el proceso de desarrollo capitalista mundial desde una muy temprana fecha. También se podría aceptar que los capitalistas mercantiles ayudaron a moldear el desarrollo de los países del Tercer Mundo desde el primer contacto. La cxistencia e importancia de los capitalistas mercantiles, sin embargo, no impliça que el modo de producción capitalista (industrial o "mercantil" - si pudiese existir dicho modo--) haya logrado un predominio.

Si esta interpretación de la historia es más correcta, pareciera no existir la necesidad por parte de Frank de asumir la posición extrema que modos precapitalistas de producción -especialmente feudal, pero esclavistas también-no prevalecieron o nunca fueron dominantes en América Latina"122

Frank aceptó estos comentarios críticos, reconociendo así algunas insuficiencias en su análisis, a la vez que afirmaba que muchos de esos y

\footnotetext{
${ }^{120}$ Cueva, op. cit., p. 5 i.

${ }^{121}$ STERnBero, op. cit., p. 78.

${ }^{122}$ Loc. cit.
} 
otros comentarios "progresistas" ("forward looking"), harian posible la inserción de problemas de dependencia y subdesarrollo en la periferia, "al nivel de las relaciones de producción"123. Debido en gran medida a éstas y otras críticas, Frank reorientó más su análisis en términos de modos de producción y de problemas de acumulación capitalista ${ }^{124}$.

\section{i) La leoría de la dependencia carece de "objetividad" académica y es de naturaleza ideológica}

Esta es la crítica más débil contra el enfoque de la dependencia, y la más característica de críticos conservadores que han contribuido en nada a! desarrollo positivo del debate sobre la dependencia. Según Gunder Frank,

"Estos críticos de derecha carecen ya sea de la perspectiva, aptitud, o interés, o de las tres, para examinar el argumento en su propio ámbito y menos aún, por supuesto, para perfeccionarlo. Su interés académico y politico reside en descalificar el argumento, y a través de sus críticas advertir a) no-especialista en su contra, recurriendo a los "descalificadores" que el positivismo ha grabado en las mentes de sus víctimas: "error" empírico y falla de "objetividad" "(nuestro ćnfasis) ${ }^{125}$.

Un ejempio de esta corriente es Klaus Knorr, quién criticó a la teoría de la dependencia por su "contenido acusatorio e inclinación ideológica" en los siguientes términos: "En estc caso no cstamos rcalmentc frente a una teoría, sino que a una literatura demonológica de protesta y movilización política, que se refiere dogmáticamente a un conjunto de demonios ricos y extranjeros"126.

En un tono parecido, aunque persiguiendo objetivos diferentes, Bath y James han declarado que "el análisis de la dependencia también se ha desvirtuado porque motiva respuestas emocionales, en pro y en contra, que oscurecen y disfrazan el valor real del enfoque" ${ }^{\prime 12}$. Los mismos autores incluso introdujeron una tipología de los teóricos de la dependencia basada principalmente en el grado de pasión o emocionalismo con que los académicos presentan sus argumentos sobre dependencia. Por ejemplo,

\footnotetext{
${ }^{123}$ Frank, "Dependence is Dead, Long Live Dependence and the Class Struggle", op. cit., pp. 98-99.

${ }_{121} \mathrm{Ver}$, por cjemplo, el análisis de André Gunder Frank y Samir Amin sobrc la presentc crisis del modelo de acumulación capitalista, y las posibles alternativas que ellos perciben, en: André Gunder Frank y Samir Amin, "Conversación Sobre la Crisis del Capitalismo", en Erncst Mandel y' otros, La Crisis Capitalista Mfundial (Lima, Perú: Ediciones Teoria y Práctica, 1975), pp. 241-264.

${ }^{125}$ FRANK, "Dpendence is Dead...", op. cit., p. 91.

120 KLAUS KNorr, The Power of Nations: The Political Economy of International Relations (New York: Basic Books, 1975), p. 280.

${ }^{127}$ C. Richard Bath y Dilmus D. James, "Dependency Analysis of Latin America: Some Criticisms, Some Suggestions", Latin American Research Review, vol. XI, N 3, 1976, p. 4.
} 
según Bath y James, la corriente "moderada" - las dos categorías restantes son "conservadora" y "radical"- dentro de la teoría de la dependencia (representada por Furtado, Sunkel y dos Santos) se caracteriza principalmente por "el grado de estridencia en sus argumentos, y por el grado de culpa que asignan a la influencia externa por problemas internos latinoamericanos" $" 128$.

Lo que éstos y otros críticos ignoran, no es sólo que no existe tal cosa como la investigación académica totalmente no-política y libre de valores, sino, además, que los orígenes históricos y el desarrollo de la teoria de la dependencia no pueden ser comprendidos aparte o separado de las luchas y realidades políticas de América Latina.

En este sentido, Cardoso resumió muy adecuadamente el desarrollo del enfoque de la dependencia cuando escribió que:

"...la materia prima de la cual se comienza es la lucha política y económica, expresada en la superficie del proceso histórico como una lucha nacional $y$ anti-imperialista. Pero, el concepto al que se llega es diferente del punto de partida, ya que (después de especificar y reseñar las relaciones entre estados, entre estos y las clases y entre ambos y el proceso productivo) demuestra las limitaciones de la comprensión inicial, y muestra cómo una estructura dada de dominación se reproduce y cuales son los posibles límites de su funcionamiento"129.

En resumen, la perspectiva teórica de la dependencia no es más "ideológica" que cualquiera otra interpretación convencional del subdesarrollo, con la diferencia que la dependencia ofrece - al contrario de otras teorías- un entendimiento histórico y dinámico de la realidad de los países periféricos.

\section{EL CONCEPTO DE LA DEPENDENCIA ESTRATEGIDA: ¿LA DEPENDENCIA ESTRUCTLRAL AL REVES?}

Los teóricos de la dependencia han concentrado, con bucnas razones, sus análisis principalmente en el impacto del imperialismo en las estructuras de clase, economias, y culturas de las sociedades actualmente subdesarrolladas. En contraste, la introducción del término "dependencia estratégica" constituye un intento por analizar lo que ocurre en los centros a medida que el imperialismo se desarrolla. En otras palabras, csta parte del ensayo es un esfuerzo de aplicación del análisis dialéctico a un aspec-

\footnotetext{
${ }^{12 B}$ Ibid., p. 9.

${ }^{120}$ Cardoso, "Notas Sobre e! Estado Actual de los Estudios de la Dependencia", op. cit., p. 101.
} 
to no suficientemente estudiado de la temática del imperialismo y la dependencia.

Como dijéramos anteriormente, por dependencia estralégica entendemos el grado en que un país capitalista avanzado depende de fuentes externas para el abastecimiento de los minerales estratégicos baratos que le son esenciales para su economía y defensa nacional. En consecuencia, un país como Japón, por ejemplo, que debe importar más de un tercio de los minerales claves que consume - en algunos casos alcanzado una dependencia con respecto a importación de un $100 \%$ - experimentaría una dependencia estratégica muy aguda.

Los paises avanzados no sólo dependen de fuentes externas -especialmente regiones del Tercer Mundo- para el abastecimiento de materias primas baratas sino que, además, también dependen de sociedades subdesarrolladas para el abastecimiento de la obra de mano barata y mercados que aquellos necesitan. Por lo tanto, en un sentido, más amplio, el concepto de dependencia estratégica incluiria estos dos componentes adicionales de la dependencia de las potencias capitalistas.

El concepto de dependencia estratégica no denota solamente una dependencia de nación a nación. Presuponemos que, en última instancia, el estado refleja los intercses de las clases gobernantes de una sociedad dada. Por supuesto, el estado en una sociedad capitalista - por ejemplo- no es una simple reflección automática y mecánica de intereses burgueses ya que conflictos internos de clase y el papel de las burocracias estatales le dan cierto grado de autonomía. De allí que estamos de acuerdo con Cotler y Fagen cuando declaran que:

"...el aparato del estado se visualiza como el representante organizado y legitimado de la clase, clases o fracciones de clase dominantes de la sociedad. Es, por lo tanto, un indicador esencial de las fuerzas sociales $y$ económicas que operan, tanto como el distribuidor e implementador clave de politicas públicas. Pero no es, en ningún sentido, una institución autónoma, ni por si sola la fuente de las políticas que promulga. En otras palabras, para las personas que comparten esta perspectiva, el análisis del poder político y de la política pública debe comenzar con el análisis de clase, ya que este último de un modo u orro moldea al primero" ${ }^{130}$.

En breve, la dependencia estratégica caracteriza, en último término, una situación en que las clases dominantes de paises industrializados dependen, para su continua prosperidad, de los recursos naturales bara-

${ }^{130}$ Julio Cotler y Richard R. FaGen, "Introduction: Political Relations Between Latin America and the United States", en J. Cotler y R. Fagen (eds.), Latin America and the United States: The Changing Poltical Realities (Stanford: Stanford University Press, 1974), p. 7. 
tos y de la obra de mano barata (necesaria, entre otras cosas, para extraer aquellos materiales) de, principalmente, paises subdesarrollados.

La dependencia estratégica de cualquier país avanzado surge básicamente de dos fuentes: a) la simple carencia física de minerales críticos y/o b) la existencia de condiciones económicas desventajosas para la explotación de materiales físicamente disponibles.

La scgunda fuente de la dependencia estratégica nos conduce a tratar otra causa absolutamente vital por la cual los países desarrollados necesitan ganar o preservar el acceso a fuentes extranjeras baratas de materias primas: la importación de recursos minerales baratos por parte de los países avanzados, les permite disminuir la velocidad de la inversión en capita! constante (c), permitiendo así no sólo aumentar la tasa de plusvalía sino que, al mismo tiempo, compensar por la tendencia de la tasa decreciente de ganancia. En las palabras de Satish Raichur:

"Las materias primas de precio bajo, al disminuir el valor de la composición orgánica del capital, se traducen en tasas más alta de ganancias. La composición orgánica del capital $(c / v+s)$ tienc un valor menor porque las materias primas baratas significan, primero, un valor más bajo para $c$, con, segundo, la diferencia entre la oportunidad de costo de las materias primas y el precio preferencial pagados por los países centros apareciendo como parte de la plusvalía (s) en el proceso de uso de las materias primas... Flujos de recursos de este tipo crean plusvalia en los países centros. Flujos de productos manufacturados desde los centros a la periferia forman el otro componente de la dialéctica de creación de plusvalia y realización de plusvalía"13:.

En resumen, el problema de la dependencia estratégica es uno de carácter cualitativo, y está ligado estrechamente al proceso de acumulación capitalista en los centros.

En el proceso de análisis de problemas relativos a la dependencia estratégica, descubrimos que varios académicos han estudiado la relación entre imperialisno y necesidad de acceso a materias primas estratégicas, especialmente del "Tercer Mundo".

Uno de los primeros en examinar la conexión entre imperialismo y las materias primas del mundo fue Lcnin mismo. En efecto, Lenin observó que:

${ }^{13}$ 'Satish RaIchur, International Inequality and National Income Distribution, trabajo presentado en la "Conferencia Sobre Desigualdad Mundial", Estes Park, Colorado, June 1977, p. 5.

Ruy Mauro Marini, el académico brasileño, tambièn destacó el efecto que tiene la importación de materias primas baratas en la composición orgánica del capital, y en la generación de plusvalia en las economias capitalistas avanzadas (ver Ruy Mauro Marini, "Dialéctica de la Dependencia: La Economía Exportadora", Sociedad y Desarrollo, vol. 1, N" 1, Santiago de Chile, marzo 1972). 
“...mientras más se desarrolla el capitalismo, más fuertemente se siente la escasez de materias primas, más intensa es la competencia y la bủsqueda de fuentes de materias primas a través de todo el mundo, y más desesperada es la lucha por la adquisición de colonias" ${ }^{\text {132 }}$.

\section{Más recientemente Gabriel Kolko ha señalado que:}

"Las naciones del Tercer Mundo pueden ser pobres, pero en última instancia el mundo industrializado necesita sus recursos más que estas naciones necesitan a Occidente, ya que la pobreza no es nada nuevo para un campesinado separado de los sectores exportadores, y ya que el comercio con estados industrializados no ha puesto fin a sus niveles de vida de subsistencia"133.

Kolko ha argumentado que una razón básica por la cual paises avanzados, tales como Estados Unidos, no pueden permitir que los países subdesarrollados se industrializen es precisamente, la necesidad imperial de preservar los depósitos de materias primas para el desarrollo económico ininterrumpido de los centros:

"En efecto, ya sea en forma intencionada o no, los bajos precios y el estancamiento económico en el Tercer Mundo benefician a las naciones industrializadas. Si alguna vez las naciones en desarrollo se industrializan hasta el punto de comenzar a consumir una porción significativa de su propio petróleo y producción minera, reducirían el abastecimiento disponible para Estados Unidos y los precios subirían"134.

Otros autores piensan que la necesidad de minerales estratégicos del extranjero es el mayor o principal determinante del comportamiento externo de los países capitalistas avanzados. Por ejemplo, Heather Dean ha escrito que:

"Aunque no niego la existencia de otras motivaciones económicas que son enfatizadas por la izquierda Marxista, yo diría que estás son secundarias a la dependencia total de la producción norteamericana con respecto a recursos naturales foráneos, que ésta dependencia es suficiente en sí miśna pará explicar la politica estadounidense, y que lleva a un conflicto fundamental entre la supervivencia de la economía norteamericana en súpresente forma y la búsqueda del desarrollo por parte del Tercer Mundo"13s.

${ }^{132}$ LENIN, Imperialism, the Highest Stage of Capitalism, op. cit., p. 101.

${ }^{133}$ Gabriel Kolko, The Roots of American Foreign Policy: An Analysis of Power and Purpose (Boston: Beacon Press, 1969), p. 50.

${ }^{234}$ Ibid., p. 60.

${ }^{125}$ Heather Dean, Scarce Resources: The Dynamic of Ametican Imperialism (Boston: New England Free Press, 1966), p. 2. 
Harry Magdoff, por otra parte, superó el estrecho análisis de Dean, al afirmar que la característica esencial del "nuevo imperialismo" que emergió a fines del siglo diecinueve, es "la lucha competitiva entre las naciones industriales (capitalistas) por lograr posiciones dominantes con respecto al mercado mundial y a fuentes de mateŕas primas, ${ }^{\prime 136}$.

Finalmente, Pierre Jalěe, el académico francés, fue más específico en su estudio del imperialismo y las materias primas al enfatizar el papel crucial que juegan los países del Tercer Mundo en el abastecimiento de recursos naturales a los centros. Como escribiese sucintamente en uno de sus trabajos: "es mi contención que la dependencia de los países industrializados respecto al Tercer Mundo... reside en el campo de las materias primas"

Benjamín Cohen, un crítico de la teoría marxista-leninista del imperialismo ha admitido que efectivamente, los países subdesarrollados son importantes para los centros como proveedores de materias primas estratégicas: "Las industrias de los países ricos indudablemente requieren acceso a minerales, combustibles e insumos agrícolas baratos, y los PMD (países menos desarrollados) son una fuente principal de abastecimiento para tales productos"138.

Sin embargo, el mismo autor ha formulado - y respondido- la siguiente interrogante:

" $¿$... representa el grado de dependencia actual una genuina 'dependencia de los países industrializados frente al Tercer Mundo', o simplemente una conveniencia económica basada en una consideración tal como accesibilidad y precio? ¿La importación de materias primas por parte de los países centros desde la periferia, es por necesidad o por elección?

Toda la evidencia sugiere que es por preferencia"139.

Esta afirmación, en verdad, revela cierto etnocentrismo y superficialidad en el análisis. Cohen, partiendo de un examen de la posición de EE. UU. respecto a recursos naturales, concluyó que ya que EE.UU. importa cobre y mineral de hierro, aún cuando posee amplias reservas' de ambos minerales, que lo mismo debe suceder con otros países capitalistas avanzados. Esto no es efectivo. Japón, por ejemplo, simplemente carece físicamente de recursos y no tiene alternativa alguna sino importar los minerales que necesita. En efecto, Japón a menudo ha sido llamado un "museo de minerales": el archipiélago posee una variedad de minerales, pero

\footnotetext{
${ }^{136}$ Harry Magdoff, The Age of Imperialism: The Economics of U.S. Foreign Policy (New York: Modern Reader, 1969), p. 15.

${ }^{137}$ Pierre Jalee, The Third World in World Economy (New York: Monthly Review Press, 1969), p. 8. Ver también P. Jalée, "La Course aux Matiéres Premieres, Le Monde Diplomatique, $\mathrm{N}^{\circ} 238$, Janvier 1974.

${ }^{138}$ Benjamin J. Cohen, The Question of Imperialism: The Political Economy of Dominance and Dependence (New York: Basic Books, 1973) p. 138.

${ }^{139}$ Ibid., p. 140.
} 
sólo en cantidades lo suficientemente grande como para abastecer una exposición de museo!

Ya hemos dicho que la dependencia estratégica de un país puede resultar, ya sea de la carencia física de recursos, o de la existencia de condiciones económicas desventajosas para la explotación de los minerales disponibles. En ambos casos los costos de no asegurar acceso a materias primas extranjeras baratas sería enorme. Tal como afirmase un estudio técnico sobre los Estados Unidos y las materias primas mundiales:

"La economía estadounidense, por supuesto, se ha beneficiado del uso de minerales foráneos. Las importaciones de la mayoría de los minerales se originaron de fuentes más baratas de abastecimiento, en países extranjeros. Esto redujo los costos que EE.UU. paga por materias primas y facilitó la exportación norteamericana de metales y bienes manufacturados en base a metal. Por lo tanto, posibilitaron ingresos realès mayores en EE.UU. de lo que se habría logrado si recursọs domésticos más caros hubiesen sido explotados"140.

En otras palabras, no es simplemente un "asunto de conveniencia" cuando los países avanzados importan minerales desde el exterior; es un problema de ventaja económica y necesidad estructural. Cualquier corte repentino o aumento substancial en el precio de las materias primas, afectaría los niveles de vida que la población de los países avanzados ha disfrutado mediante el consumo masivo de los recursos naturales del Tercer Mundo y, más aún, agravaría la tendencia de la tasa declinante de ganancia al aumentar el valor de la composición orgánica del capital.

Al Szymanski, otro crítico de la teoría marxista-leninista del imperialismo, y de su vinculación con los minerales del Tercer Mundo, se ha concentrado especificamente en el trabajo de Harry Magadoff, afirmando que Magdoff:

"1) exagera la importancia de los países periféricos como fuentes de abastecimiento de materias primas; 2) confunde la realidad de las importaciones de materias primas desde esos países con el problema de sí esas son las linicas maneras de obtener tales recursos, o si son meramente las más baratas; 3) desestima las posibilidades de desarrollo de materiales sintéticos que podrían ser más caros pero que, en todo caso, desempeñarían las funciones de recursos disponibles sólo de países periféricos"141.

${ }^{140}$ International Economic StUdies Instrtute "Dependence of the Industrialized World on Imported Materials", en Raw Materials and Foreign Policy (Washington, D.C.: International Economic Studies Institute, 1976), p. 12.

${ }^{141}$ AL. Szymanski, "Capital Accumulation on a World Scale and the Necessity of Imperiatism", The Insurgent Sociologist, vol. $\mathrm{VH}, \mathrm{N}^{\circ} 2$, Spring 1977, pp. 46-47. 
Ignorando - tal como lo hiciera Cohen - la situación de recursos de otros países avanzados fuera de EE.UU. y no reconociendo la naturaleza cualitativa de la ventaja derivada por parte de los países centro de la importación de materias primas baratas desde el exterior Szymanski declaró que "gran parte de la importación norteamericana de matérias primas ocurre no porque no existan fuentes de abastecimiento potenciales en otros lugares, sino porque depósitos muchos más ricos de los minerales importados existen en países del Tercer Mundo que en Estados Unidos y en otros países capitalistas avanzados"142.

Coincidiendo con nuestra línea de argumentación, Magdoff respondió a la crítica de Szymanski de la siguiente manera:

"Lo que èl (Szymanski) afirma es que si fuese necesario nosotros - es decir, la economía capitalista- podríamos arreglarnoslas sin las materias primas del tercer mundo. Verdad, pero ¿cómo?: "Nosotros" podríamos decirle a las corporaciones multinacionales que se fuesen al infierno junto con su lucha por lograr control monopólico, crecimiento y ganancias. "Nosotros" podriamos reducir la producción y el uso de autos, "nosotros" podríamos racionar la distribución de bienes que utilizan materias escasas, "nosotros" podríamos inventar y producir substitutos más caros. "Nosotros", especialmente la clase obrera y los pobres, podríamos apretarnos los cinturones y reducir nuestro nivel de vida. Si uno pasa del mundo real al ámbito de la especulación uno puede soñar de muchas cosas, sin preocuparse demasiado acerca de cómo el suẹno se hará realidad o cuáles serán sus consecuencias ${ }^{143}$.

Finalmente, Edward Fried, un economista, trató de minimizar la importancia de los minerales para los países avanzados afirmando, primero, que las exportaciones de materias primas constituyen una porción comparativamente pequeña del comercio mundial. Según Fried, "las exportaciones de materias primas en 1973 fueron de 45 billones de dólares, menos de $1 / 4$ del comercio total en productos primarios y $8 \%$ del total del comercio mundial. De esta proporción, las exportaciones de materias primas no-renovables tales como minerales y metales sumaron sólo 13 billones de dólares" ${ }^{\prime 14}$. El mismo autor indicó además que el papel de los paises subdesarrollados en este intercambio internacional no es tan importante como comunmente se piensa: "la mayor parte del comercio en productos primarios ocurre entre países industrializados (incluyendo a la Unión Soviética y Europa Oriental). Estos países importan más

142 Ibid., p. 48.

${ }^{143}$ Harry Magdoff, "How to Make a Molehill out of a Mountain: Reply to Szimanski", The Insurgent Sociologist, vol. vil, $\mathrm{N}^{\circ} 2$, Spring 1977, p. 11.

14tEdward R. Fried, "International Trade in Raw Materials: Myths and Realities", Science, vol. 191, No 4228, Feb. 20, 1976 , p. 643. 
productos primarios (en términos de valor) de entre ellos mismos que desde países en vías de desarrollo"145.

Fried, sin embargo, no capta el punto clave: si bien en términos cuantitativos la porción de la periferia en el comercio internacional de las materias primas es relativamente pequeña ${ }^{146}$, esta porción es absolutamente indispensable en un sentido cualitativo para el crecimiento continuo y para la supervivencia de las economías de los países capitalistas avanzados.

Más aún, ya que las naciones periféricas controlan el mercado mundial de varios minerales estratégicos, si los países avanzados necesitan bauxita, por ejemplo, deberán depender exclusivamente de los países subdesarrollados para su abastecimiento. También es un poco ingenuo pensar que porque la industria minera en algunos países-centros ha, a través de los años, representado un porcentaje declinante de sus PNB relativo a otros sectores, que no existe dependencia estratégica alguna. El hecho es que, a pesar que el sector mineral en algunas sociedades avanzadas ha llegado a ser menos importante que otros sectores revelando así la tendencia industrial del capitalismo moderno, históricamente, los minerales han crecido en importancia en términos absolutos (como lo revelan los datos básicos de importación y consumo), y son aún extremadamente esenciales para el crecimiento económico en dichos países.

Estas últimas observaciones nos conducen a otro punto importante acerca del fenómeno de la dependencia estratégica: la dependencia estratégica de las naciones avanzadas es, en gran medida, un resultado del proceso histórico de expansión capitalista. A medida que el imperialismo creaba la dependencia sufrida actualmente por los países subdesarrollados, al mismo tiempo, se profundizaba la dependencia de las potencias desarrolladas con respecto a las materias primas críticas del Tercer Mundo.

Incidentalmente, Marx había notado la existencia de un fenómeno similar cuando -al escribir sobre el colonialismo en China e India- - sugirió que "no sólo Asia se está poniendo más dependiente con respecto a Europa, sino que Europa también, dialécticamente, se está haciendo más dependiente de Asia"147. En otras palabras, la dependencia estratégica que experimentan los países avanzados es la contraparte dialéctica de la

${ }^{145}$ Ibid., pp. 643-644.
${ }^{146}$ Sin embargo, los

${ }^{146}$ Sin embargo, los países subdesarrollados han aumentado notablemente su porcentaje de participación en la producción total de algunos minerales estratégicos tales como mineral de hierro y bauxita: en 1913 las naciones subdesarrolladas producian un $3 \%$ de la producción mundial total de mineral de hierro y un $15 \%$ de la del petrólco, mientras que en 1965 ya producian un $37 \%$ y un $65 \%$ respectivamente. Su porcentaje de participación en la producción mundial de bauxita aumentó de un $21 \%$ en 1928 a un $69 \%$ en 1965 . Más encima, las naciones subdesarrolladas controlan el mercado - abasteciendo un $60 \%$ o más de las exportaciones mundiales- de varias materias primas críticas, incluyendo el petróleo, el estaño, la bauxita, cl cobre, el manganeso y otros.

${ }^{147}$ Ver Shlomo Avineri, Marx on Colonialism and Imperialism-(Garden City, N.Y.: Anchor Books, 1970), p. 16. 
dependencia estructural característica de las sociedades subdesarrolladas, y ambos tipos de dependencia están relacionados con el proceso histórico del desarrollo capitalista mundial.

Con el propósito de clarificar las̀ relaciones de dependencia que existen entre centro $y$ periferia, hemos disenado un modelo simple que aparece a continuación:

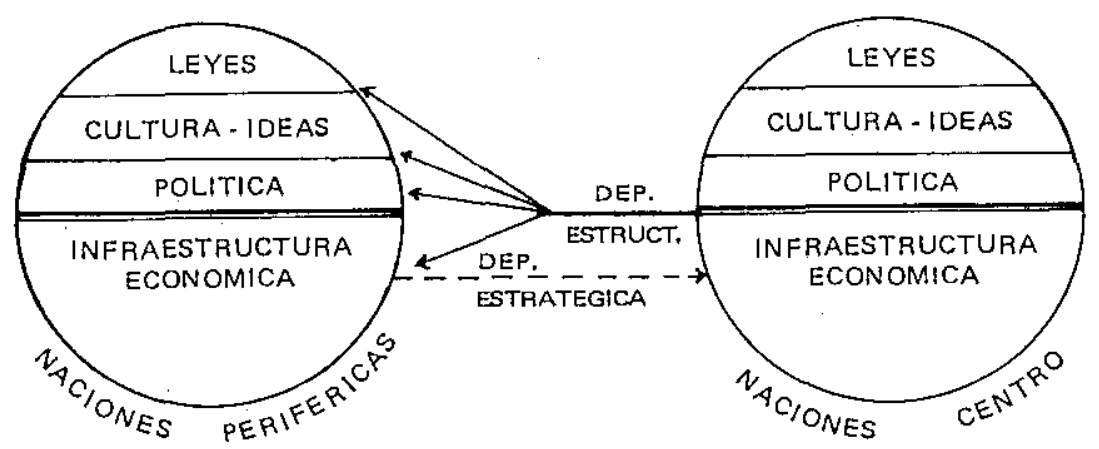

De acuerdo a este análisis, la dependencia "estratégica" de las naciones-centro equivale a una situación que podría identificarse como dependencia sectorial (que afecta el "normal funcionamiento" de las economías capitalistas de los centros), a diferencia de una dependencia generalizada o dependencia "estructural" de las naciones periféricas (que afecta a las economías, estructuras de clase, política, cultura, etc., de las sociedades subdesarrolladas), ambas constituyendo aspectos complementarios de un a misma realidad.

En otras palabras, la dependencia estratégica no representa -como algunos hacen creer- una situación de dependencia en que el mundo desarrollado se doblega ante los países subdesarrollados que poseen materias primas y obra de mano baratas. Esto sería absurdo. Lo que afirmamos es que los países capitalistas avanzados experimentan una situación de dependencia sectorial contraria a la dependencia estructural-generalizada de las naciones periféricas.

Algunos analistas y comentaristas han tratado de oscurecer las vitales diferencias que existen entre estas dos situaciones de dependencia, al hablar de una creciente interdependencia o dependencia mutua, entre potencias desarrolladas y países subdesarrollados ricos en recursos naturales que, en vista de la crisis del petróleo, debería facilitar el logro de la paz y cooperación internacional para beneficio de la humanidad. En realidad, la crisis petrolera de 1973 dio mayor ímpetu a una tendencia creciente de legitimización de una verdadera ideología de la interdepen- 
Heraldo Muñoz / Cambio y continuidad en el Debate sobre la Dependencia y el...

dencia $^{148}$, mediante la cual algunos académicos y líderes políticos han pretendido hacer equivaler a la dependencia estructural de las naciones subdesarrolladas con la dependencia estratégica de los países avanzados.

Por ejemplo, Henry Kissinger, uno de los principales proponentes de la ideología de la interdependencia, visualizó el problema en los siguientes términos:

"El futuro de la paz y del progreso puede estar determinado por nuestra respuesta a las necesidades impuestas por nuestra interdependencia económica.

...Todas las naciones son parte de un sistema cconómico global. Si ese sistema ha de florecer debe descansar en la firme fundación de seguridad, justicia y oportunidad para todos aquellos que desean participar en

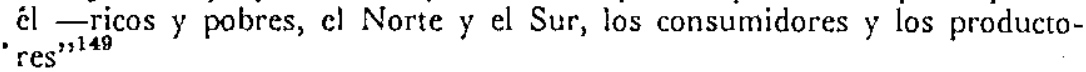

En otro documento titulado "Una Era de Interdependencia: Desastre Común o Comunidad", Kissinger fue más explicito afirmando que "un mundo interdependiente requiere no solamente de recursos sino la visión y creatividad de todos nosotros... Debemos reconocer que el interés común es la única prueba válida del interés nacional ${ }^{150}$.

Otros a su vez han postulado que cl embargo petrolero marcó cl establecimiento definitivo de la "dependencia mutua a nivel mundial":

"...la situación actual de escasez mundial de recursos naturales posibilita, por primera vez, que paises desarrollados y en desarrollo conciban las relaciones económicas internacionales en términos de dependencia y reciprocidad mutua efectiva"15 1 (énfasis nuestro).

${ }^{148}$ El volumen de artículos, discursos y libros escritos sobre el tema de la "interdependencia" es demasiado grande como para transcribirlo aquí. Algunos ejemplos de la literatura incluyen Robert S. Ingersoll, "Economic Interdependence and Common Defense", Department of State Bulletin, October 7, 1974; Emile Van Lennep, "The Interdependence of Nations", The OECD Observer, $N^{\circ}$ 67, December 1973; "The Management of Interdependence", The oecd Observer, $N^{\circ}$ 82, July-August 1976; Richard Rosecrance y Arthur Stein, "Interdependence: Myth or Reality", World Politics, No 1, October 1973; Miriam Camps, The Management of Interdependence: A Preliminary View (New York: Council on Foreign Relations, 1974); Prime Mfinister Harold Wilson, World Economic Interdependence and Trade in Commodities (London: Her Majesty's Stationary Office, May 1975); Ali A. Mazrui, "The New Interdependence" in Guy Erb and Valeriana Kallab (eds.), op. cit., pp. 38-54; Lester R. Brown, World, Without Borders (New York: Vintage Books, 1973); Richard N. Gardner, "To Make the World Safe for Interdependence", The Inter-Dependent, July-August $1975 \mathrm{y}$, en general, la mayor parte de los ensayos publicados en la revista. The Inter-Dependent.

1 "Henry Kissinger "Speech begore the Fourth Ministerial Meeting of the Unctad", The Secretary of State, Office of Media Services, U.S. Department of State, May 6, 1976.

${ }^{160}$ Henry Kissinger "An Age of Interdependence: Common Disaster or Community", The Department of State Bulletin, October 14, 1974, p. 499.

is 'Overseas Development Council "Self-Reliance and International Reform" Communique on Development Issues, $\mathrm{N}^{\circ} 24, \mathrm{p} .5$. 
Desde una perspectiva similar, una fuente gubernamental japonesa afirmó que:

"Para planificar el desarrollo sin tropiezos de la economía mundial, es esencial para los paises avanzados y los productores de malerias primas, que se den cuenta que son muluamente dependientes y que deben cultivar un espíritu de cooperación para satisfacer sus necesidades mutuas. Esto puede ser logrado a través del impulso al desarrollo de las materias primas, para así proveer una oferta estable de dichos recur$\operatorname{sos}^{\prime 152}$ (énfasis nuestro).

O, como dijera un documento del Departamento de Estado norteamericano en forma muy sucinta: "de muchas maneras, y como nunca antes, los países industrializados y los países menos desarrollados se encuentran (después de la crisis petrolera) en un estado de dependencia mutua" (énfasis nuestro).

Una consecuencia de la realización creciente de que existe una situación de dependencia estratégica por parte de los países avanzados, aunque oscurecida por conceptos tales como "interdependencia" y/o "dependencia mutua", ha sido la agudización de la rivalidad inter-imperialista con vistas a asegurar el acceso preferencial a fuentes externas de materias primas baratas, especialmente en las regiones subdesarrolla$\operatorname{das}^{154}$.

Un autor, por ejemplo, ha observado, especificamente, crecientes fricciones entre Estados Unidos y Japón:

"...existen buenos motivos para creer que una parte creciente de las importaciones de materias primas por parte de Japón provendrán de América Latina...

Japón, por lo tantọ, está penetrando a una zona considerada por largo tiempo como nuestro patio trasero, al mismo tiempo en que Estados Unidos se hace más dependiente de sus fuentes latinoamericanas tradicio-

${ }^{152}$ Ministry of Internationą: Trade and Industry of Japan, "Overseas Economic Cooperation", en Japan Instiiute of International Affairs (eds.) The White Papers of Japan: 7974-1975 (Tokyo: Japan Instilute of International Affairs, 1976), p. 140-141.

${ }^{153}$ U.S. Department OF STATE, The United States and the Third World (Washington D.C.: U.S. Government Printing Office, July 1976), p. 13.

${ }^{154}$ Una manifestación reciente de csta rivalidad inter-imperialista ocurrió cuando durante julio de 1978, el gobierno de Argelia canceló un acuerdo con dos compañias norteamericanas (El Paso y Tenneco, Inc.) que implicaba la entrega de 351 billones de pies cúbicos de gas al año, por un período de 20 años. Los beneficiarios de la cancelación fueron dos corporaciones de slemania Occidental (Briggita y Thyssengas), cada una de las cuales recibirá anualmente 13,5 billones de pies cưbicos de gas. Lo interesante es que las dos companías alemanas tenian "un acueróo tentativo con SONATKACH (la corporación de petróleo nacional de Argelia) que dependia del resultado de las negociaciones del contrato norteamericano". Ver "Algeria Cancels Two Gas Accords with U.S. Firms", The Wall Street Journal, July 5,1978 , p. 4. 
nales de materias primas, $y$ sus relaciones con la región se complican por problemas de nacionalismo y conflictos de interés económico. En este contexto, parecería existir una seria posibilidad de confliclo con Japón en torno al acceso a las materias primas que afectan significalivamente la red-seguridad-política-economia de los Estados Unidos ${ }^{3155}$ (énfasis nuestro).

En completa concordancia con lo anterior, otro analista ha expresado que:

"Japón y varios países curopeos han concluido que deben diseñar sus propias 'diplomacias de los recursos naturales' como el núcleo central de sus politicas extranjeras, y de allí que América Latina sea en algunos respectos un nuevo campo de batalla para la competencia entre los paises industrializados" (énfasis nuestro) ${ }^{156}$

No es sorprendente entonces, que el gobierno de EE.UU. haya demostrado bastante interés y preocupación por posibles conflictos en torno al acceso a las materias primas escasas:

"Tenemos razón para prcocuparnos por el problema de la oferta y de los precios de materias primas de Europa y Japón. Si, por ejemplo, su abastecimiento de cobre fuese interrumpido por algún cierre de producción repentino en América Latina o en países africanos, los japoneses sin duda penetrarían al mercado norteamericano a obtener abastecimientos. Ei precio que los consumidores pagan se veria, por lo tanto, afectado"157

El problema de los recursos naturales se ha complicado aún más, con el surgimiento, en la escena mundial, de nuevos competidores en la búsqueda mundial de materias primas no renovables tales como Brasil. Efectivamente, Brasil se ha transformado en un importante inversionista en los recursos naturales de otros países. Por ejemplo, el monopolio petrolifero gubernamental PETROBRAS está activamente buscando pctróleo en el Medio Oriente, Venezuela, Bolivia y Perú. Algo similar está sucediendo con respecto a fertilizantes de fosfato.

En resumen, parecería que la crisis petrolera de 1973 agudizó una rivalidad ya creciente entre países avanzados que eventualmente,

\footnotetext{
${ }^{153}$ WENDELL. W. WOODBURY, The U.S. and Japan and Latin America's Mineral Resources, Senior Seninar in Foreign Policy, U.S. Department of State, 16th. Session, 1973-1974, p. 1.

${ }^{156}$ C. Fred Bergsten, "U.S. Latin American Economic Relations to 1980: The International Framework and Sonc Possible New Approaches" en .Commission on United States - Latin American Relations, The Americas in a Changing W'orld (New York: New York Times Book Co., 1975), p. 189.

${ }^{157}$ Councit on International Economy Policy, Special Reporl: Critical Imported Malerials (Washington, D.C.: U.S. Government Printing Office, December 1974), p. 47.
} 
podría conducir a conflictos reales. Según las palabras de John C. Loebb, ex-ejecutivo de la ITT y ex-director para EE.UU. de la compañía Nippon Electric: "las principales naciones industrializadas participan actualmente en una guerra cconómica mundial. Los principales adversarios son los Estados Unidos, Alemania y Japón" "158.

En conclusión, la crisis del petróleo demostró dramáticamente la existencia de una situación de dependencia estratégica por parte de los países capitalistas avanzados, agudizó la rivalidad y competencia inter-imperialista por fuentes escasas de materias primas y, además, fue responsable de aumentos en nivelcs de inversión y asistencia económica de los centros hacia los países subdesarroliados ricos en recursos naturales, como una manera importante de asegurar acceso preferencial a los minerales estratégicos de la periferia. Este último fenómeno fue la principal preocupación de un estudio más amplio realizado por este investigador. El presente ensayo, por lo menos, sirvió para exponer la base teórica de aquella investigación empírica, y para examinar temas de gran importancia dentro del cuadro teórico de la dependencia.

${ }^{158}$ 3.C. Loesв citado por Richard J. Barnet y Ronald E. Müller, Glohal Reach: The Power of Multinational Corporations (New York: Simon and Schuster, 1974), p. 195. 